\title{
Experimental characterisation of the periodic thermal properties of walls using artificial intelligence
}

\author{
David Bienvenido-Huertas a, *, Carlos Rubio-Bellido a, Jaime Solís-Guzmán a , \\ Miguel José Oliveira ${ }^{\mathrm{b}}$ \\ ${ }^{a}$ Department of Building Construction II, University of Seville, 41012 Seville, Spain \\ ${ }^{\mathrm{b}}$ Instituto Superior de Engenharia, Universidade do Algarve, 8005-139 Faro, Portugal
}

\section{A R T I C L E I N F O}

\section{Article history:}

Received 5 October 2019

Received in revised form

19 April 2020

Accepted 12 May 2020

Available online 18 May 2020

\section{Keywords:}

Periodic thermal transmittance

Energy demand

ISO 13786

Multilayer perceptron

Random forests

In-situ

\begin{abstract}
A B S T R A C T
The energy performance of a building is affected by the periodic thermal properties of the walls, and reliable methods of characterising these are therefore required. However, the methods that are currently available involve theoretical calculations that make it difficult to assess the condition of existing walls. In this study, the characterisation of the periodic thermal variables of walls using experimental measurements and methods as described in ISO 13786 was assessed. Two regression algorithms (multilayer perceptron $[\mathrm{MLP}]$ and random forest $[\mathrm{RF}]$ ) and input variables obtained using two experimental methods (the heat flow meter and the thermometric method) were used. The methods gave accurate estimates, and better statistical parameter values were given by the RF models than the multilayer perceptron models. For all the periodic thermal variables, the percentage differences between the actual values and the estimated values given by the RF algorithm were low. The heat flow meter and the thermometric methods can both be used to characterise accurately the periodic thermal properties of walls using the RF algorithm. The variables specific to each method, including the wall thickness and the date of construction, affected the accuracies of the models most strongly.
\end{abstract}

() 2020 Elsevier Ltd. All rights reserved.

\section{Introduction}

Arguably, the two most important goals of the 21st century are the prevention of further environmental degradation and a reduction in the rate of climate change [1]. The latter is becoming increasingly severe, at least partly due to the large amounts of greenhouse gases (GHGs) being emitted through energy production. The pressing need to decarbonise the production of energy was recognised at the Paris Climate Conference of 2015, at which 195 countries committed to a marked decrease in GHG emissions. However, there is still some way to go towards the effective mitigation of climate change. Attempts to decrease GHG emissions and the difficulty of decreasing GHG emissions were described in "United in Science" [2], a report published as part of the United Nations Climate Action Summit of 2019. The main points findings of

\footnotetext{
* Corresponding author. Higher Technical School of Building Engineering, Ave. Reina Mercedes 4A, Seville, Spain.

E-mail addresses: jbienvenido@us.es (D. Bienvenido-Huertas), carlosrubio@us.es (C. Rubio-Bellido), jaimesolis@us.es (J. Solís-Guzmán), mjolivei@ualg.pt (M.J. Oliveira).
}

the report were that $\mathrm{CO}_{2}$ emissions are continuing to increase by $1 \%$ each year, fossil fuel is still dominant despite increased renewable energy production, and $\mathrm{CO}_{2}, \mathrm{CH}_{4}$, and $\mathrm{N}_{2} \mathrm{O}$ concentrations are $146 \%$, $275 \%$, and $122 \%$ higher, respectively, compared with the preindustrial period (before 1750).

Countries and communities should therefore set themselves more stringent goals than at present, to allow the environment to be protected for future generations. The European Union has established a roadmap for developing a low-carbon economy in accordance with the agreement to eliminate virtually all GHG emissions in all sectors made at the 2015 conference. For the building sector, the goal is to decrease GHG emissions to the atmosphere by $90 \%$ compared with 1990 [3]. This goal will have an important effect on the climate due to the high percentage of energy consumed by, and GHG emissions from, activities in existing buildings.

The need to improve the energy performance of existing buildings is clear. The main energy consumption in existing buildings is due to heating, ventilation, and air conditioning systems [4,5], meaning that energy conservation measures focused on decreasing energy consumption are required in these areas. The 
thermal behaviour of the envelope of a building needs to be characterised in order to identify the most appropriate energy conservation measures for the building and to ensure that the building meets the energy use regulations in place [6,7]. For many studies, the aim has been to analyse the effects on the energy demands of buildings of thermal variables such as stationary thermal transmittance $[8,9]$ and linear thermal transmittance [10]. However, the importance of thermal inertia and periodic thermal properties of buildings are of increasing interest. Better understanding of these properties could make it possible to construct net zero carbon energy buildings (nZEB) in warm climates in particular, given their greater applicability to energy consumption in warm than cold regions [11]. The effects of the periodic thermal properties of buildings have been investigated by many authors. For example, di Perna et al. [12] analysed three wall types with different thermal masses in a school building and determined appropriate combinations of periodic thermal transmittance and internal areal heat capacity. Rossi and Rocco [13] analysed four heavy and four light walls to evaluate the appropriateness of the periodic variable limits set in the Decreto Ministeriale 26/6/2009 [14] and found by Di Perna et al. [12]. The results reported by Di Perna et al. were found to have limitations caused by the dependence of internal areal heat capacity on the external climate, nevertheless Rossi and Rocco were able to identify ways of decreasing the energy demands of buildings in general terms. Stazi et al. [15] determined the combined effects of the decrement factor and internal areal heat capacity in a windowless room in Italy and found that the best annual performance was given by the average thermal inertia properties of a decrement factor of 0.072 and an internal areal heat capacity of 33 $\mathrm{kJ} /\left(\mathrm{m}^{2} \mathrm{~K}\right)$ ). Aste et al. [16] studied six facade types using building model simulations and found that the use of periodic thermal variables decreased the cooling demand. They found that $20 \%$ less cooling was required for a wall with a high thermal inertia than for a wall with a low thermal inertia. Baglivo et al. [17] performed multi-objective optimisations to identify the most acceptable configurations for nZEB envelopes for buildings in the Mediterranean and found that the surface masses of the external walls strongly affect the performances of buildings. Fernandes et al. [18] and Rodrigues et al. [19] found that walls in cold regions should have high thermal inertia while those in warm regions should have low thermal inertia. Many building envelope designs using walls with low thermal inertia can be used to decrease energy demand in warm regions.

Calculation procedures or simulation processes are required to allow periodic thermal properties to be characterised [20]. ISO 13786 [21] is a calculation procedure for assessing the periodic thermal behaviour of a building envelope, and the calculation procedure has the same limitations as that for calculating the stationary thermal transmittance described in ISO 6946 [22]. Asan [23] investigated the effects of thickness and type of material on the decrement factor and time shift for 26 construction materials. The layers and their thermal properties must be assessed accurately to allow periodic thermal properties to be estimated with any confidence. Three main methods can be used to achieve this, namely (i) endoscopic analysis [22,24], (ii) analysis of technical documents [25], and (iii) estimation using analogous constructions [22,25]. Analogous constructions provide the least certainty, and smaller errors are achieved using endoscopy and technical documents $[22,26]$. However, correct characterisation of wall layers is limited for most buildings because endoscopic techniques damage the building and technical documentation is not usually sufficient. Several procedures for characterising the stationary thermal transmittances of existing walls have therefore been developed in recent years. The most commonly used methods in recent years are the heat flow meter method (HFM) and the thermometric method (THM) [27]. The main differences between these are the variables used in the calculations, which imply a need for different in situ monitoring procedures. HFM requires heat fluxes and THM requires internal surface temperatures to be measured. The different variables used cause the monitoring data to have different errors. Meng et al. [28] found heat flux measurement errors of up to $26 \%$ but surface temperature measurement errors of only $6 \%$. The most accurate results have been found to be achieved using an appropriate envelope orientation [29], a high thermal gradient during the tests [30], and unaltered elements [31].

The stationary thermal transmittance method contains procedures for making appropriate estimates for existing walls as long as the walls are in adequate states of repair. Rotilio et al. [32] found differences of $10 \%-15 \%$ between measured and estimated values for walls damaged by earthquakes and other eans. There are, however, no acceptable methods for determining all of the variables that affect periodic thermal properties, although some methods using hot boxes have been used to characterise these types of variables [33]. There are some limitations on the use of hot boxes for walls, making such methods something of a challenge. In the study presented here, our aim was to combine different commonly used procedures to obtain stationary thermal transmittance using estimated periodic thermal variables. The advantages of performing thermal characterisations using these procedures are that the procedures are widely known and that stationary thermal transmittance can also be estimated. Two approaches using different regression algorithms (multilayer perceptron (MLP) and random forest (RF)) are used. Each approach is based on previous studies using other thermal characterisations that gave acceptable results [34,35]. First, use of MLPs allows estimates to be made using the results of HFM with THM input variables (internal surface temperature and air temperature), and eliminating errors in the results using a theoretical total internal heat transfer coefficient [36]. Second, the stationary thermal transmittance data determined using the ISO 6946 method were analysed using MLPs and RFs [34]. It was necessary to determine this in order to allow validation of the results obtained by experiment; these results reflect the potential for this variable to be determined using the algorithms used here.

The potential for the use of regression algorithms to estimate stationary thermal transmittance using various theoretical and experimental methods is clear. However, as mentioned above, methods for determining periodic thermal properties are still required. Therefore, in this study we assessed the possibility of determining different thermal variables that would allow the periodic thermal behaviour of a wall to be represented using regression algorithms that have been used in previous studies. Periodic thermal variables (periodic thermal transmittance, periodic thermal transmittance time shift, decrement factor, internal thermal admittance, internal thermal admittance time shift, external thermal admittance, and external thermal admittance time shift) were estimated using input variables determined using HFM or THM. The aim was to develop methods for the in-situ characterisation of the periodic thermal properties of buildings without knowledge of the compositions of the existing walls, thereby making these methods more widely available to engineers and auditors for the correct characterisation of the behaviours of existing buildings, to allow effective energy conservation measures to be established, and to make it easier to meet the goal of decreasing GHG emissions from buildings by 2050 . 


\section{Methodology}

\subsection{ISO 13786: theory and calculation procedure}

ISO 13786 [21] allows dynamic thermal characterisation of the walls of a building to be performed using a series of variables to determine the thermal behaviour of each wall, including temporal variations. In the standard, sinusoidal variations in the air temperature outside the envelope are assumed to generate heat fluxes and sinusoidal variations in the internal temperature (see Fig. 1). ISO 13786 was developed using the results of a study performed by Carslaw and Jaeger [37], in which the relationship between the sinusoidal variations in the external and internal temperatures and the heat flux were analysed.

The procedure in ISO 13786 requires information on the

$$
\mathrm{U}=\frac{1}{1 / h_{e}+\sum_{i=1}^{n} \frac{d_{i}}{\lambda_{i}}+1 / h_{i}}
$$

where $\lambda_{\mathrm{i}} \lambda \mathrm{i} \lambda \mathrm{i} \lambda_{i}[\mathrm{~W} /(\mathrm{m} \cdot \mathrm{K})]$ and $d_{i}[\mathrm{~m}]$ are the thermal conductivity and thickness of layer $i$ of the wall, respectively, and $h_{i}$ and $h_{e}[\mathrm{~W} /$ $\left.\left(\mathrm{m}^{2} \mathrm{~K}\right)\right]$ are the total internal and external thermal transmittance coefficients, respectively, determined as specified in ISO 6946.

The procedure in ISO 13786 involves use of a heat transfer matrix for each layer of the element $\left(Z_{m n}\right)$ (see Eq. (2)). A heat transfer matrix for air gaps $\left(Z_{a}\right)$ is also used (see Eq. (3)). The specific thermal capacity of the air gap is disregarded.

$$
\begin{aligned}
& Z_{m n}=\left(\begin{array}{ll}
Z_{11} & Z_{12} \\
Z_{21} & Z_{22}
\end{array}\right) \\
& Z_{11}=Z_{22}=\cosh (\xi) \cos (\xi)+j \cdot \operatorname{senh}(\xi) \operatorname{sen}(\xi) \\
& Z_{12}=-\frac{\delta}{2 \lambda}\{\operatorname{senh}(\xi) \cos (\xi)+\cosh (\xi) \operatorname{sen}(\xi)+j \cdot[\cosh (\xi) \operatorname{sen}(\xi)-\operatorname{senh}(\xi) \cos (\xi)]\} \\
& Z_{21}=-\frac{\lambda}{\delta}\{\operatorname{senh}(\xi) \cos (\xi)-\cosh (\xi) \operatorname{sen}(\xi)+j \cdot[\cosh (\xi) \operatorname{sen}(\xi)+\operatorname{senh}(\xi) \cos (\xi)]\}
\end{aligned}
$$

configuration and properties of the wall layers. It therefore requires the values of three thermophysical properties of the materials to be known. These are the specific thermal capacity (c), the density $(\rho)$, and the thermal conductivity $(\lambda)$. The procedure therefore has the same limitations as the ISO 6946 method for calculating the stationary thermal transmittance [38]. In ISO 6946, stationary thermal transmittance is characterised by considering the element to be a set of homogeneous and parallel layers. Each layer has a thermal resistance determined by the thermal conductivity $(\lambda \mathrm{i})$ and thickness (di). The stationary thermal transmittance is defined as the reciprocal of the sum of the resistances of the layers in the element and the limiting layers,

$$
Z_{a}=\left(\begin{array}{cc}
1 & \\
-R_{a} & \\
0 & 1
\end{array}\right)
$$

In Eq. (3), $\xi$ [dimensionless] is the relationship between the thickness $(d)$ and periodic penetration depth $(\delta)$ of a thermal wave in the material in the layer (see Eq. (4)) and $\left.R_{a}\left[\left(\mathrm{~m}^{2} \mathrm{~K}\right) / \mathrm{W}\right)\right]$ is the thermal resistance of the air gap.

$$
\delta=\sqrt{\frac{\lambda T}{\pi \rho c}}
$$

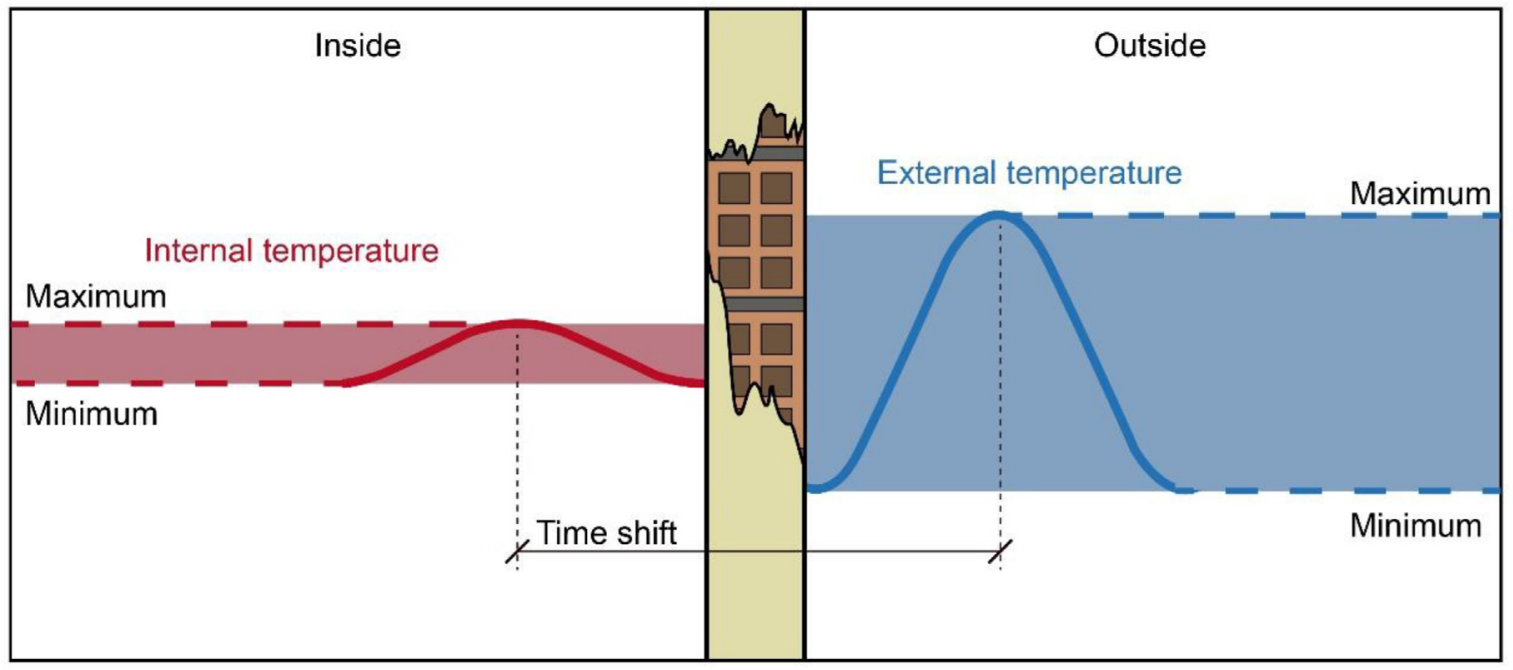

Fig. 1. Scheme showing the sinusoidal temperature variations considered in ISO 13786. 
The total heat transfer matrix of an element is obtained by multiplying the matrices of the different layers together, beginning with the internal layer $\left(Z_{1}\right.$ is to the innermost layer of the element) (see Eq. (5)). This matrix is used to obtain the matrix for heat transfer between the two environments (see Eq. (6)) together with the heat transfer matrices for the internal limit layer (Eq. (7)) and external limit layer (Eq. (8)).

$Z=\left(\begin{array}{ll}Z_{11} & Z_{12} \\ Z_{21} & Z_{22}\end{array}\right)=\prod_{i=N}^{1} Z_{i}$

$Z_{\mathrm{ee}}=Z_{\mathrm{sN}} \cdot Z \cdot Z_{\mathrm{s} 1}$

$Z_{s 1}=\left(\begin{array}{cc}1 & \\ -1 / h_{i} & \\ 0 & 1\end{array}\right)$

$Z_{S N}=\left(\begin{array}{cc}1 & \\ -1 / h_{e} & \\ 0 & 1\end{array}\right)$

The periodic variables used in the standard can be determined from the elements in the heat transfer matrix. The variables used in the standard are shown in Table 1 . All variables were considered in this study.

\subsection{Regression models}

The method used here involved assessing the possibility of estimating the periodic thermal variables described in Section 2 using two wall monitoring procedures, HFM and THM. Two

Table 1

Periodic thermal variables used in ISO 13786.

\begin{tabular}{ll}
\hline Variable & Calculation \\
\hline Periodic thermal transmittance & $Y_{12}=-\frac{1}{\left|Z_{12}\right|}$ \\
Time shift periodic thermal admittance & $\phi=\frac{T}{2 \pi} \arg \left(Z_{12}\right)$ \\
Decrement factor & $\mathrm{f}=\frac{\left|Y_{12}\right|}{U}$ \\
Internal thermal admittance & $Y_{11}=-\frac{\left|Z_{11}\right|}{\left|Z_{12}\right|}$ \\
Time shift internal side & $\phi_{11}=\frac{T}{2 \pi} \arg \left(Y_{11}\right)$ \\
External thermal admittance & $\kappa_{22}=\frac{T}{2 \pi} \arg \left(Y_{22}\right)$ \\
Time shift external side & $\kappa_{1}=\frac{T}{2 \pi}\left|\frac{Z_{11}-1}{Z_{12}}\right|$ \\
\hline
\end{tabular}

regression algorithms were used, which were trained using a dataset containing the results of 22,820 tests performed in a previous study. A flowchart of the study procedure is shown in Fig. 2.

\subsubsection{Regression algorithms: $M L P$ and $R F$}

Two regression algorithms (MLP and RF) were used, with different success rates in previous studies [34,35]. The algorithms and the factors analysed in each algorithm are described below.

2.2.1.1. MLP. MLP is a type of artificial neural network. The MLP algorithm simulates the structure of the brain in order to solve a problem [39], and can be used for regression or classification. This approach is successful because of the universal approximation capacity that characterises the algorithm [40-42]. The MLP model in this case had three layer types (see Fig. 3 (a)), an input layer (corresponding to the input layer in the model), one or several hidden layers, and an output layer (corresponding to the output variable of the model). There were several connected neurons in each layer. The output value of the model was the sum of the values of the neurons in the previous layers weighted using synaptic weights from activation, transfer, and propagation functions. The estimate given by the model $\left(\widehat{Y}_{M L P}\right)$ can be expressed using the equation

$\widehat{Y}_{M L P}=\sigma\left(\sum_{k=1}^{M} w_{l k}^{(2)} \sigma\left(\sum_{j=0}^{d} x_{j} w_{k j}^{(1)}\right)\right)+w_{10}^{(2)} y_{0}$

where $w_{l k}^{(2)}$ is the weight of the output layer, $\sigma$ is the activation function, $x_{j}$ is the value of the input layer, $w_{k j}^{(1)}$ is the weight of a hidden layer, and $w_{10}^{(2)}$ and $y_{0}$ are the weight and the value, respectively, of the bias neuron in a hidden layer.

Adjustment of the synaptic weights is essential for the model because this allows the difference between the actual and the estimated value of each value to be minimised. The MLP models were therefore trained by back propagation $[43,44]$ using the Broyden-Fletcher-Goldfarb-Shanno algorithm [45], which is a quasi-Newtonian method. Similar procedures were used to design MLPs in previous studies [34,35]. The models were trained using a 10 -fold cross validation procedure, which was expected to decrease substantially the variance of the model results [46]. The 10 -fold cross validation involved dividing the training dataset randomly into 10 subsets 10 times. In each set of 10 subsets, nine were used to train the MLP and the other was used to test the MLP. This process was repeated 10 times. The MLP performance was determined by calculating the average value for all 10 times the process was performed. Only models with one hidden layer were considered, and the number of neurons was varied between one and 15 until the configuration giving the best performance was identified.

2.2.1.2. $R F$. The RF algorithm is a tree-type algorithm. Models using $\mathrm{RF}$ algorithms are effective for large datasets [47] and give smaller errors and variances than other algorithms [48,49]. A RF algorithm creates a set of classification and regression tree (CART) models. The output value of a RF model is the mean estimate for each tree (see Fig. 3(b)). A CART model is a predictor model with a reverse tree structure (in which the internal nodes are the input variables of the dataset, the arches are the possible values of the variables, and the leaves are the CART variables). Like MLPs, CART models can be used for classification and regression.

To train an RF model, the training dataset is divided into Nbootstrapped sample sets [49], each of which generates a CART model. Each node of each CART is divided using a subset of randomly selected $\mathrm{m}$ predictors, which decreases the influences of 


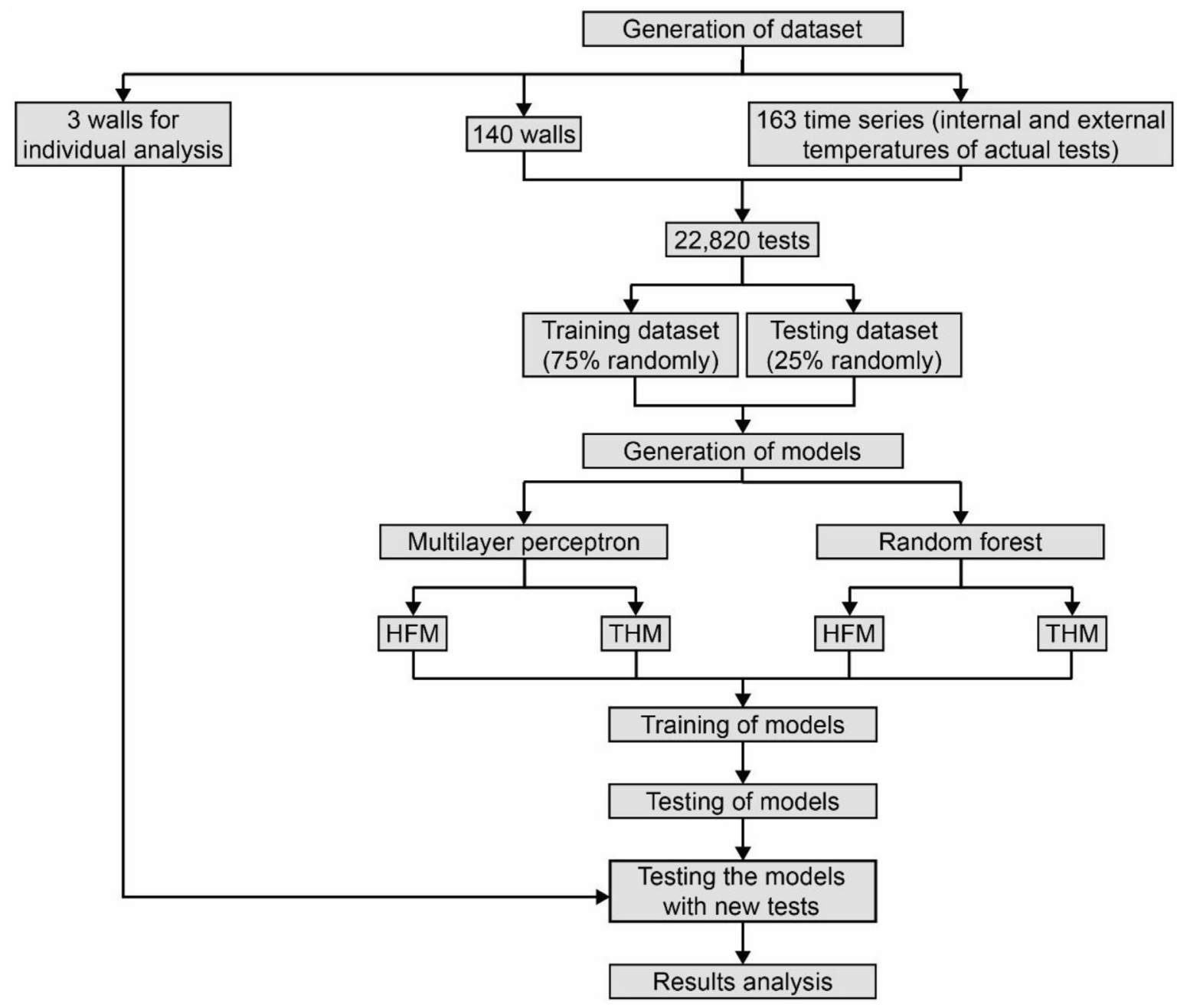

Fig. 2. Flowchart of the study.

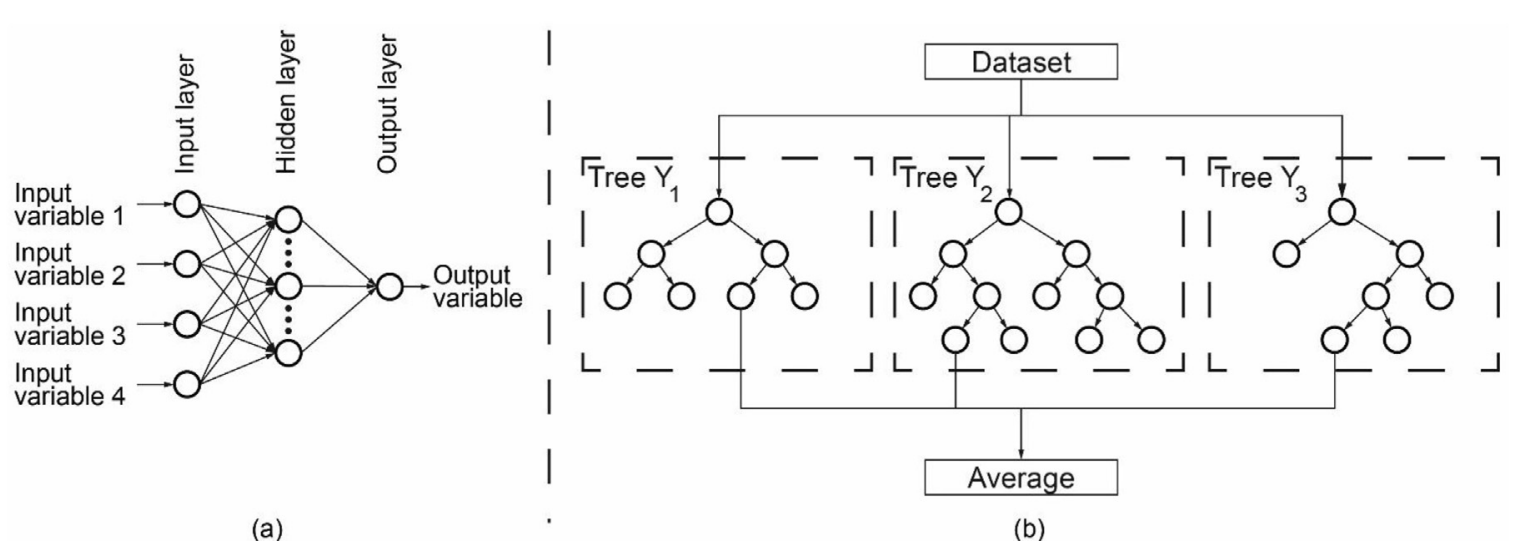

Fig. 3. Schemes of the (a) multilayer perceptron regression model and (b) random forest regression model.

the strongest predictors [50]. The estimate given by the RF model is obtained by calculating the average of the estimates given by the set of CARTs (see Eq. (19)). The estimate given by the model therefore depends on the number of trees used in the RF model [51]. Therefore, the RF models used in this study had between two and 50 trees. The most appropriate number of trees was defined as the number above which the model did not improve but the computing time required to train the model increased.

$$
\widehat{Y}_{R F}=\frac{1}{T} \sum_{t=1}^{T} \widehat{Y_{t}}
$$

In Eq. (19), $\widehat{Y}_{t}$ is the output of the $t$-th tree and $T$ is the number of trees. 
Heat flow meter method (HFM)

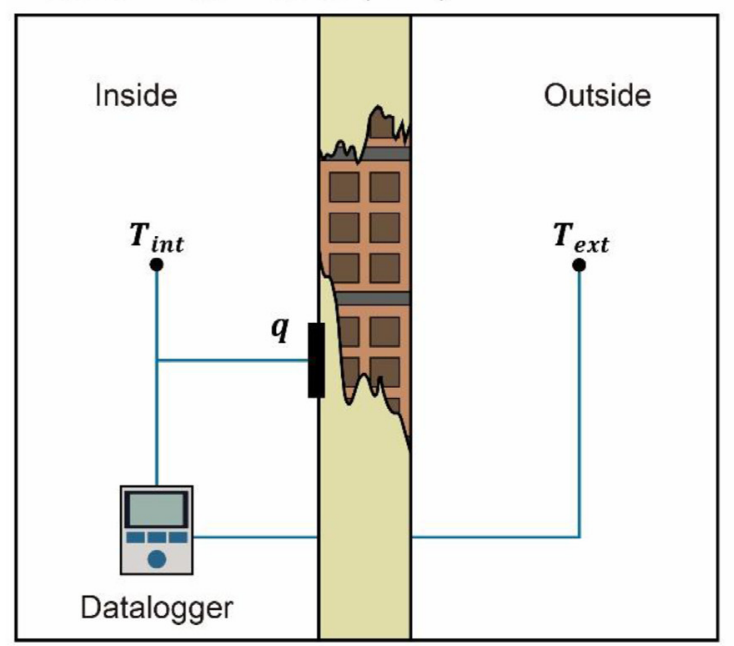

Thermometric method (THM)

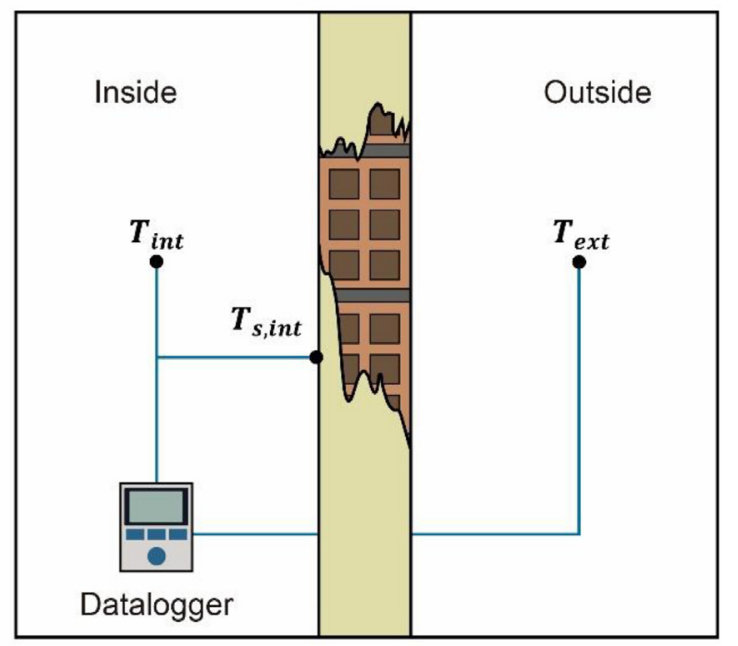

Fig. 4. Schemes for the in-situ measurement models used to determine the input variables.

Table 2

Input and output variables used in each approach.

\begin{tabular}{|c|c|c|c|}
\hline Approach & Algorithm & Input variables & Output variables \\
\hline HFM & MLP, RF & $\bar{T}_{\text {int }}, \max \left(T_{\text {int }}\right), \min \left(T_{\text {int }}\right), \bar{T}_{\text {ext }}, \max \left(T_{\text {ext }}\right), \min \left(T_{\text {ext }}\right), \bar{q}, \max (q), \min (q)$, thickness, time, period & $\begin{array}{l}Y_{12}, \phi, f, Y_{11}, \phi_{11} \\
Y_{22}, \phi_{22}, \mathrm{k}_{1}, \mathrm{k}_{2}\end{array}$ \\
\hline THM & MLP, RF & $\bar{T}_{i n t}, \max \left(T_{\text {int }}\right), \min \left(T_{\text {int }}\right), \bar{T}_{\text {ext }}, \max \left(T_{\text {ext }}\right), \min \left(T_{\text {ext }}\right), \bar{T}_{s, i n t}, \max \left(T_{s, i n t}\right), \min \left(T_{s, i n t}\right)$, thickness, time, period & $\begin{array}{l}Y_{12}, \phi, f, Y_{11}, \phi_{11} \\
Y_{22}, \phi_{22}, k_{1}, k_{2}\end{array}$ \\
\hline
\end{tabular}

\subsubsection{Dataset and approaches used}

As mentioned in Section 1, the aim of the study was to identify a method for making in-situ estimates of the periodic thermal properties of walls by combining different stationary thermal transmittance monitoring approaches to avoid the limitations of previously developed methods. Such a method would correctly estimate the stationary and periodic thermal properties of a wall. Two approaches were used to deal with the input variables to the regression model, one for each of the monitoring procedures used (the HFM and the THM), as shown in Fig. 4. The main difference between the methods was that HFM involved measuring the heat flux but THM involved measuring the internal surface temperature of the element. The different approaches gave different input variables (see Table 2). The relationships between the input variables for the internal and external air temperatures were therefore considered. The input variables had the same structure for both approaches. The mean, minimum, and maximum values determined by performing instantaneous measurements were used. Three input variables were used, as in previous studies, namely wall thickness, test duration, and date of construction. Given the context of the study (in Spain), it was important to identify three different periods of construction, namely P1 (before the normative NBE-CT79 standard [52]), P2 (after the NBE-CT-79 standard but before the Spanish Technical Building Code [53]), and P3 (after the Spanish Technical Building Code). The output variables for each approach corresponded to the periodic thermal variables shown in Table 1 , i.e., $\mathrm{Y}_{12}, \phi$, f, $Y_{11}, \phi_{11}, Y_{22}, \phi_{22}, \mathrm{k}_{1}$, and $\mathrm{k}_{2}$. Separate MLP and RF models were designed for each variable using both approaches. The MLP and RF models were assessed until the optimum configurations for the criteria shown in Subsection 3.1 had been identified.

The envelope elements of key interest here are the walls, because these are of primary relevance in determining the effectiveness of the thermal characterisation procedure. They are easier to characterise than other envelope elements such as roofs, which may have different thicknesses. The dataset was similar to that used in a previous study [35] and was obtained by performing twodimensional transitory simulations. The simulations were based on real tests using simulated facade models (see Fig. 5). A total of 140 different types of facade were modelled. The designs of the facades were based on types described in the Catalogue of Construction Elements [54] and types derived from various studies in which the facades of Spanish real estate parks were catalogued [55,56]. The models used were therefore suitable for the types of facades used in the construction periods typical of housing estates in Spain. For walls with insulating material layers, several layers were used, in particular, expanded polystyrene, mineral wool, polyurethane, and extruded polystyrene. These materials were selected because they are the most common types of insulation used in buildings [57]. The fact that the walls were designed during the simulation process meant that the characteristics of the layers (material, thickness, and thermal properties) were fully understood. A dataset accurately reflecting the periodic thermal properties of each simulated facade was therefore available. Each of the 140 types of facade was used with 163 real-time indoor and outdoor air temperatures. Therefore, 22,820 different combinations of wall types and times were used. The surface thermal resistances contained in ISO 6946:2007 were used as the horizontal heat flux boundary conditions. These were $0.13 \mathrm{~m}^{2} \mathrm{~K} / \mathrm{W}$ for internal conditions and $0.04 \mathrm{~m}^{2} \mathrm{~K} / \mathrm{W}$ for external conditions. This was because it is recommended in ISO 6946:2007 that these surface thermal resistance values are used for typical building envelopes under normal operating conditions (i.e., the interior temperature is within an acceptable range for comfort).

Two datasets were used because two different approaches were used. One dataset was suitable for HFM and the other for THM. Accurate information was available for the layers and the thermal 


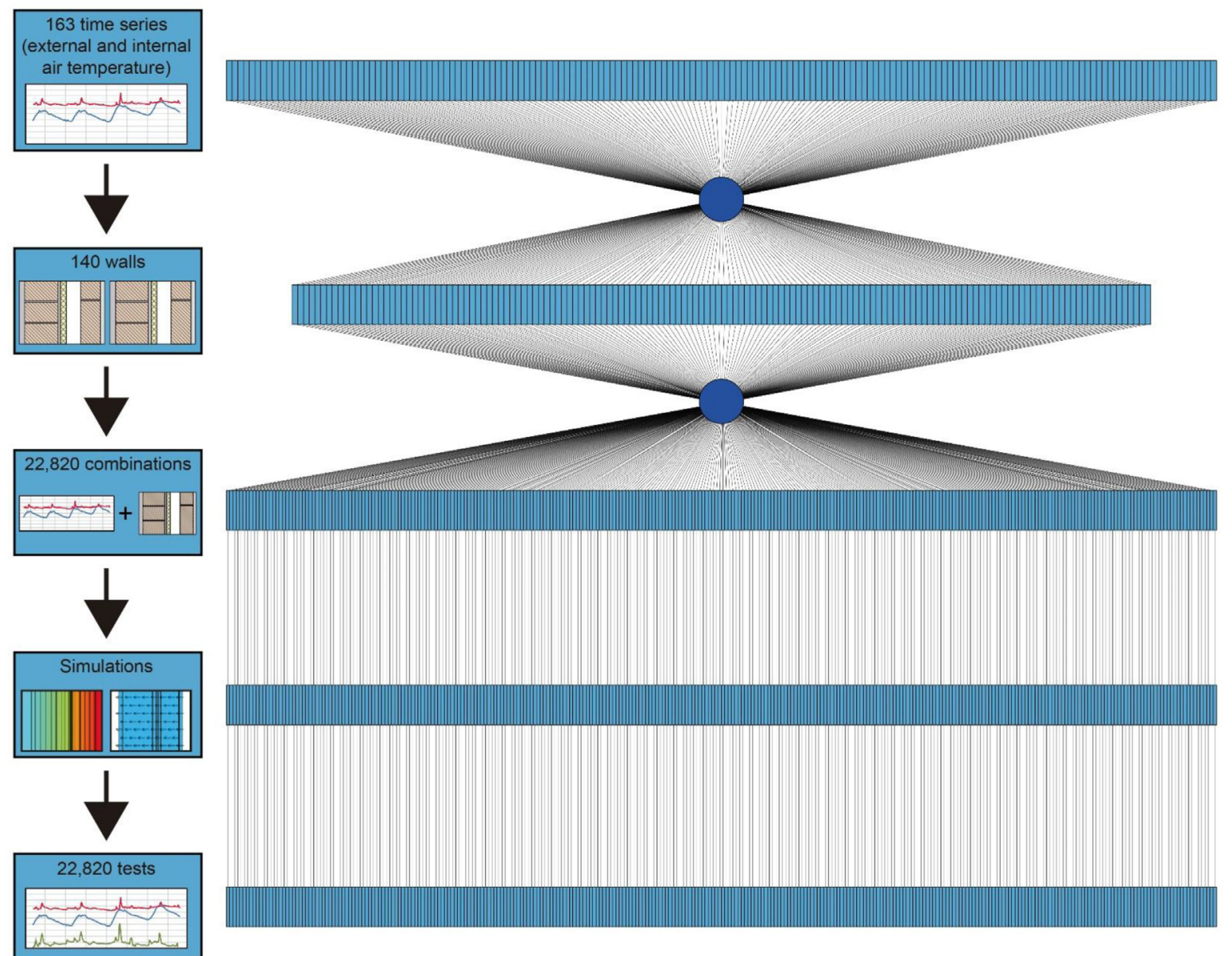

Fig. 5. Flowchart of the simulation process.

properties of the 140 walls, therefore periodic thermal properties could be determined using ISO 13786 (see Eqs. (9)-(17)). Each test was used as an observation of the relevant dataset, so the sum of the durations of the randomly selected instances was the full test duration. Each dataset was randomly divided into smaller datasets for training and testing. The training dataset contained 17,115 instances (75\% of the full dataset) and the testing dataset contained 5705 instances (25\% of the full dataset). Three walls in any dataset were not considered (see Table 3). Each wall belonged to a different representative period for buildings in Spain. The estimates made using the models for the three case studies were assessed by analysing the estimates made for the three walls that were not considered.

The accuracy of each model was assessed using three statistical parameters, namely the coefficient of determination $\left(R^{2}\right)$ (Eq. (20)), the mean absolute error (MAE) (Eq. (21)), and the root-meansquare error (RMSE) (Eq. (22)). These parameters were selected because they are widely used to assess regressions [58,59].

$R^{2}=100\left(1-\frac{\sum_{i=1}^{n}\left(a_{i}-p_{i}\right)^{2}}{\sum_{i=1}^{n}\left(a_{i}-\bar{a}_{i}\right)^{2}}\right)$

$M A E=\frac{\sum_{i=1}^{n}\left|a_{i}-p_{i}\right|}{n}$
$R M S E=\left(\frac{\sum_{i=1}^{n}\left(a_{i}-p_{i}\right)^{2}}{n}\right)^{1 / 2}$

In Eqs. (20)-(22), $a_{i}$ is the actual value, pi is the predicted value, and $n$ is the number of instances in the dataset (training or testing).

\section{Results and discussion}

The procedures used to calculate the periodic thermal variables had the same limitations as that used to calculate stationary thermal transmittance in ISO 6946 because accurate information on the thermal properties of each layer in the element was required. As for existing buildings, correct characterisation of the periodic thermal properties of the envelope elements is a considerable challenge.

As mentioned in Section 3, the estimated periodic thermal properties were analysed using different approaches for the HFM and THM monitoring procedures. Both procedures were analysed using the MLP and RF regression algorithms.

First, the variability described by the statistical parameters $R^{2}$, MAE, and RMSE was analysed using different MLP and RF configurations (by varying the number of nodes in the hidden layer for the MLP models and varying the number of trees for the RF models). The evolutions of the statistical parameters in the models for the HFM approach are shown in Figs. 6 and 7. The RF model performance improved as the number of trees increased until a plateau was reached. The optimal number of trees in the RF models of the periodic variables was generally between 40 and 45 . The 
Table 3

Thermophysical properties of the walls selected for individual analysis.

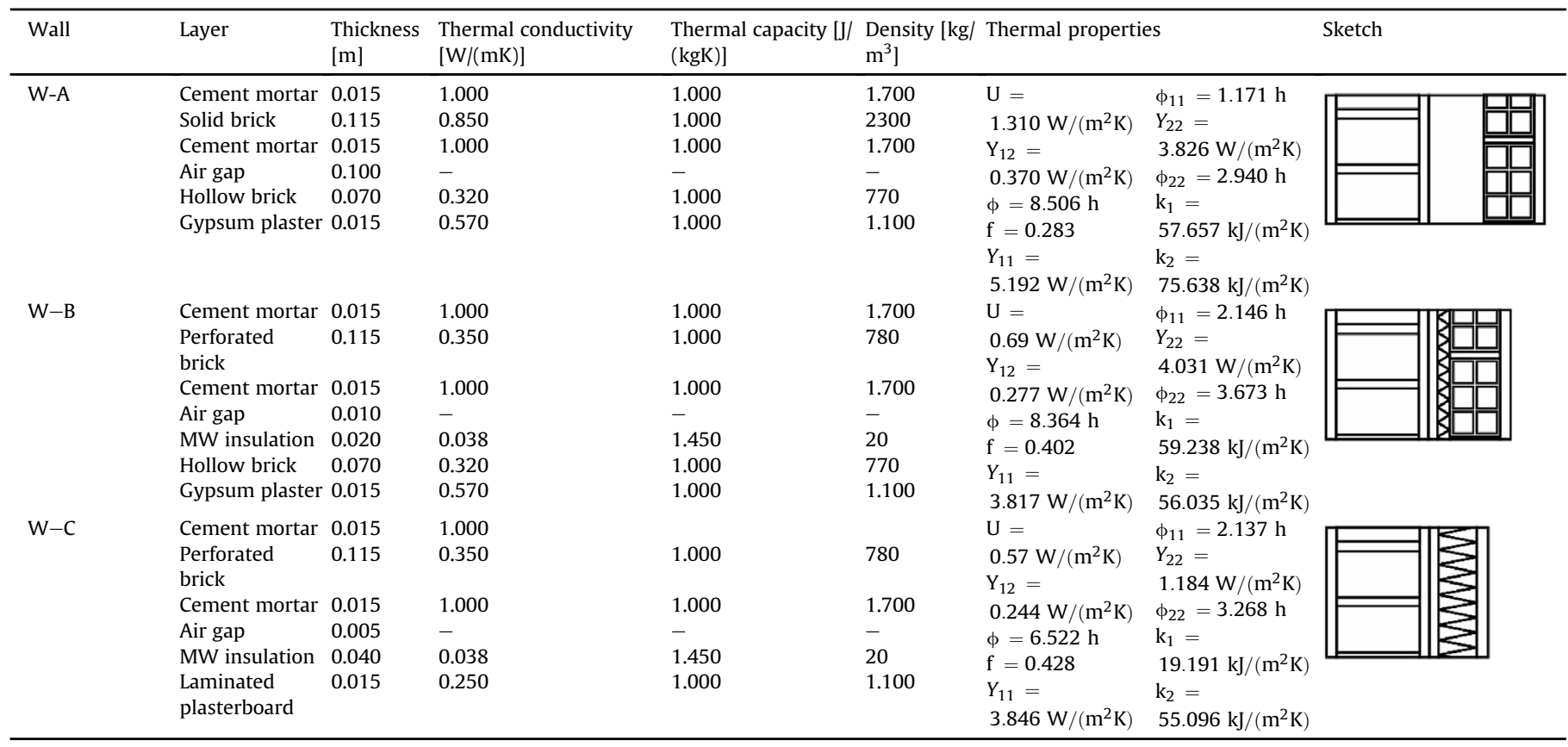

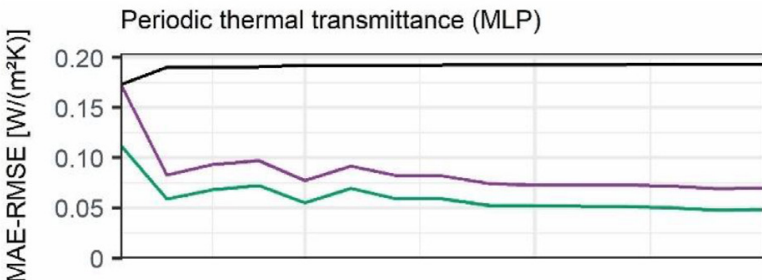

Decrement factor (MLP)

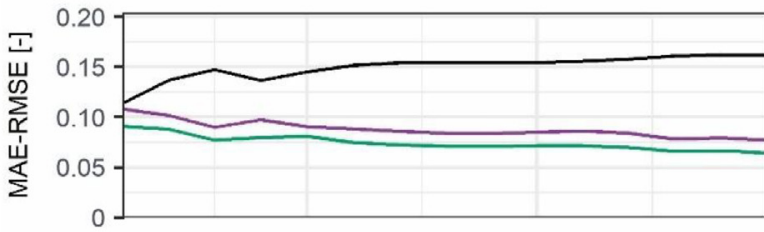

Periodic thermal transmittance time shift (MLP)

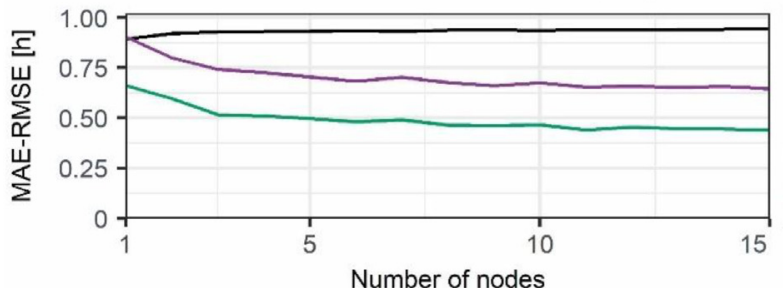

Periodic thermal transmittance (RF)

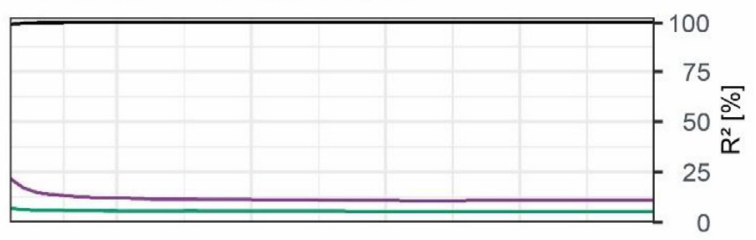

Decrement factor (RF)

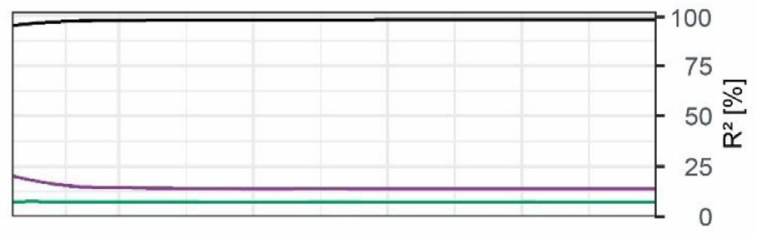

Periodic thermal transmittance time shift (RF)

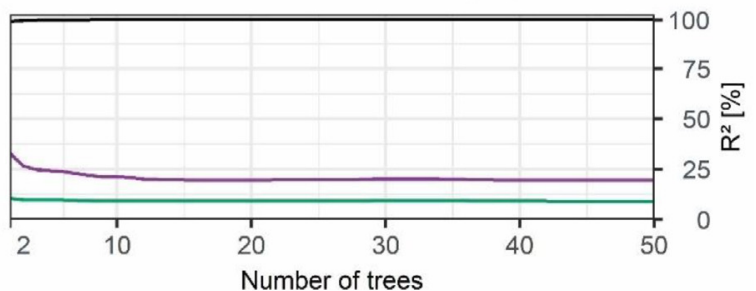

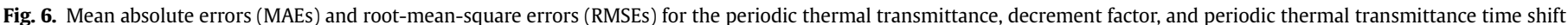

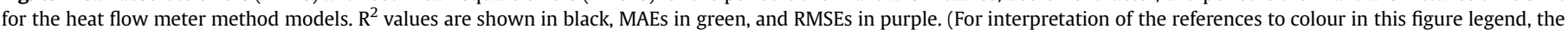
reader is referred to the Web version of this article.) 


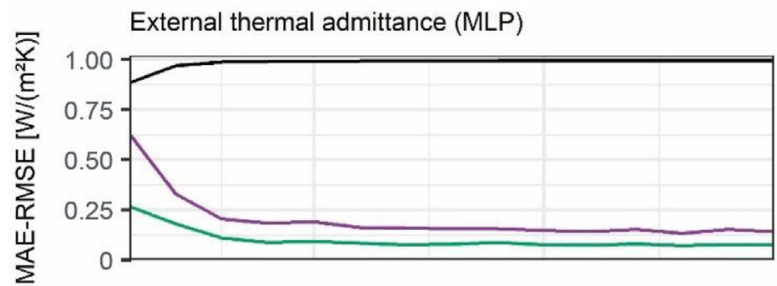

External thermal admittance time shift (MLP)

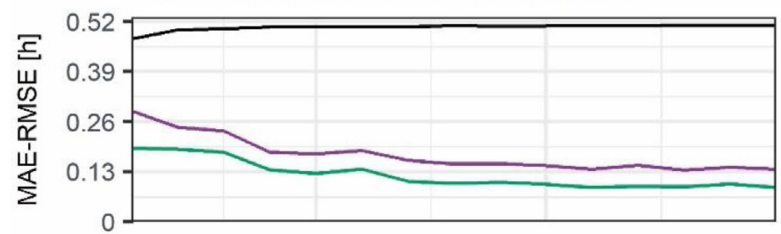

Internal thermal admittance (MLP)

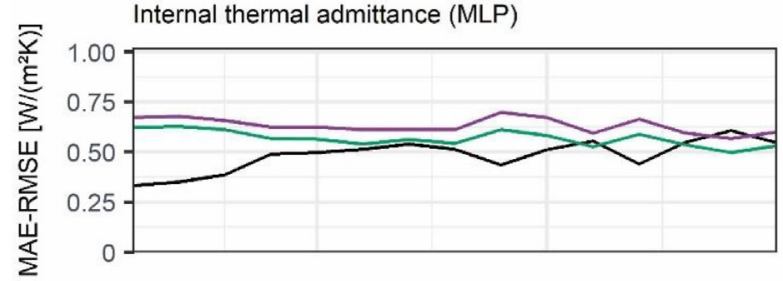

Internal thermal admittance time shift (MLP)

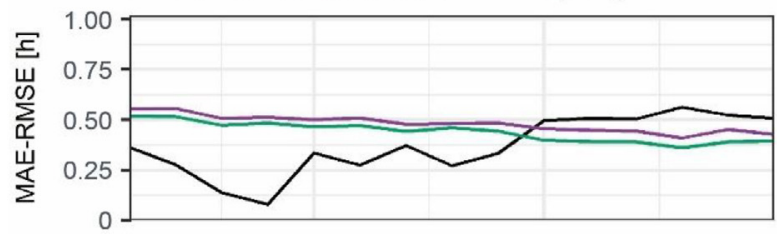

External areal heat capacity (MLP)
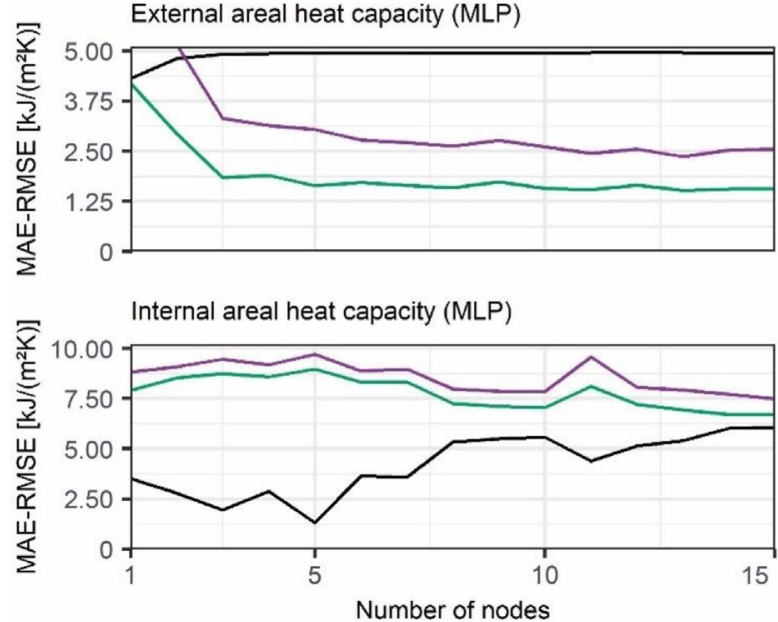

External thermal admittance (RF)

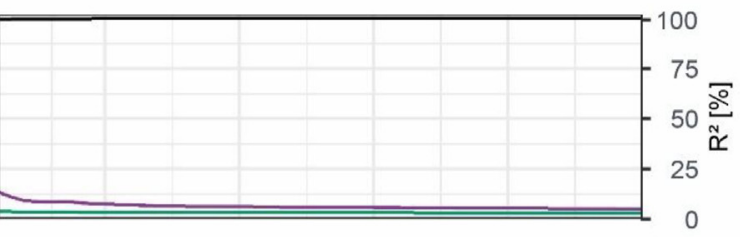

External thermal admittance time shift (RF)

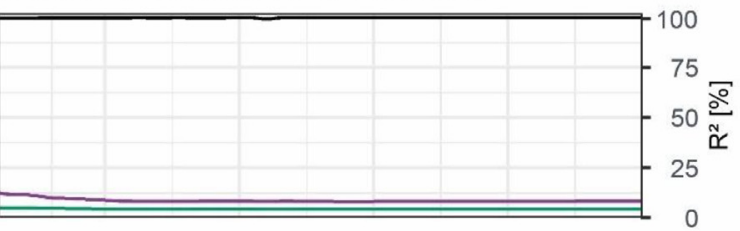

Internal thermal admittance (RF)

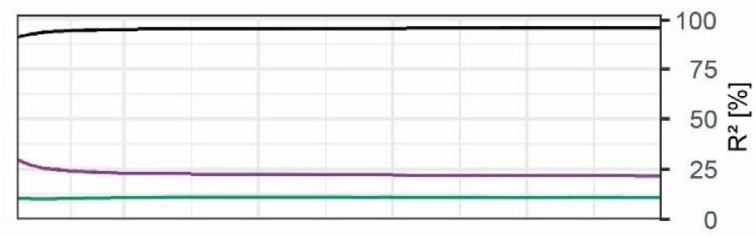

Internal thermal admittance time shift (RF)

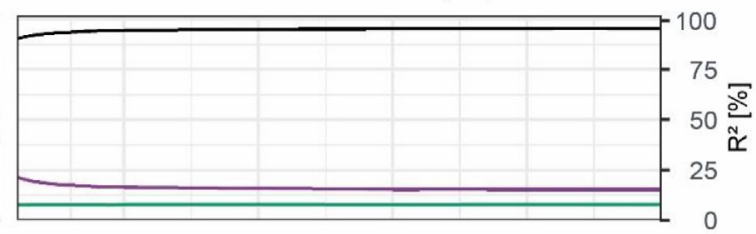

External areal heat capacity (RF)

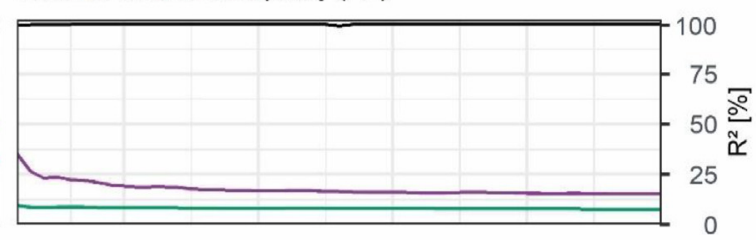

Internal areal heat capacity (RF)

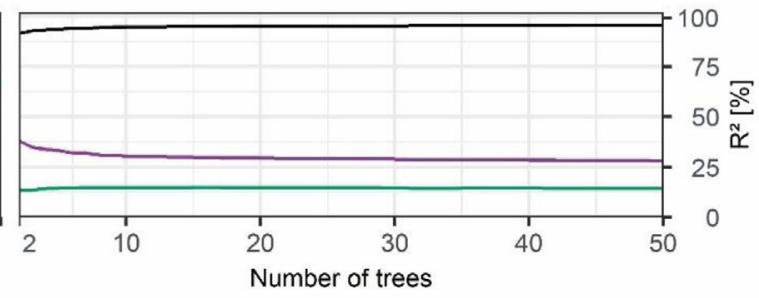

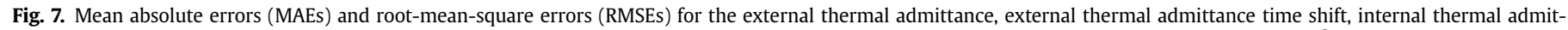

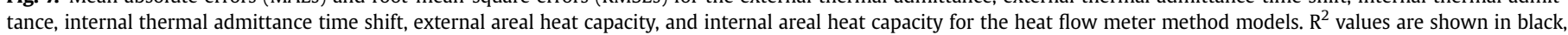
MAEs in green, and RMSEs in purple. (For interpretation of the references to colour in this figure legend, the reader is referred to the Web version of this article.)

most appropriate number of nodes for the MLPs was between 11 and 15 , depending on the periodic thermal variable being considered.

The RF models performed better than the MLP models (see Tables 4 and 5). The periodic variables in the RF models had determination coefficients $>95 \%$, but the periodic variables in the MLP models had determination coefficients $<70 \%$. The RF models had determination coefficients between $0.44 \%$ and $39.08 \%$ better than the MLP models, but had MAE and RMSE values that were, on average, $75.62 \%$ and $65.65 \%$, respectively, lower than for the MLP models. This indicates that the statistical parameters were better for the RF models than for the MLP models. The configurations and performances of the models were similar regardless of whether THM or HFM was used, but there were some differences. First, the determination coefficients were $0.13 \%-2.11 \%$ lower for the THM models than for the HFM models. Second, the MAEs and RMSEs were $16.09 \%$ and $41.27 \%$ higher, respectively, for the THM models than for the HFM models. As mentioned in Section 3, THM uses 
Table 4

Performances of the optimal multilayer perceptron models for the heat flow meter method models and thermometric method models.

\begin{tabular}{|c|c|c|c|c|c|c|}
\hline \multirow[t]{2}{*}{ Variable } & \multirow{2}{*}{$\frac{\mathrm{HFM}}{\mathrm{R}^{2}[\%]}$} & \multirow[b]{2}{*}{ MAE } & \multirow[b]{2}{*}{ RMSE } & \multirow{2}{*}{$\frac{\mathrm{THM}}{\mathrm{R}^{2}[\%]}$} & \multirow[b]{2}{*}{ MAE } & \multirow[b]{2}{*}{ RMSE } \\
\hline & & & & & & \\
\hline Periodic thermal transmittance & 96.62 & 0.0477 & 0.0691 & 96.02 & 0.0531 & 0.0757 \\
\hline Decrement factor & 80.46 & 0.0658 & 0.0779 & 75.26 & 0.0751 & 0.0862 \\
\hline Periodic thermal transmittance time shift & 94.04 & 0.4463 & 0.6519 & 93.79 & 0.5067 & 0.6725 \\
\hline External thermal admittance & 99.49 & 0.0716 & 0.1334 & 98.88 & 0.1000 & 0.1998 \\
\hline External thermal admittance time shift & 98.10 & 0.0871 & 0.1289 & 97.76 & 0.0912 & 0.1400 \\
\hline Internal thermal admittance & 60.61 & 0.4976 & 0.5679 & 47.23 & 0.5671 & 0.6294 \\
\hline Internal thermal admittance time shift & 56.31 & 0.3596 & 0.4090 & 34.54 & 0.4304 & 0.4771 \\
\hline External areal heat capacity & 99.22 & 1.5214 & 2.3667 & 98.47 & 1.9103 & 3.3239 \\
\hline Internal areal heat capacity & 60.27 & 6.7024 & 7.7119 & 49.74 & 7.3093 & 8.3316 \\
\hline
\end{tabular}

Table 5

Performances of the optimal random forest models for the heat flow meter method models and thermometric method models.

\begin{tabular}{|c|c|c|c|c|c|c|}
\hline \multirow[t]{2}{*}{ Variable } & \multirow{2}{*}{$\frac{\mathrm{HFM}}{\mathrm{R}^{2}[\%]}$} & \multirow[b]{2}{*}{ MAE } & \multirow[b]{2}{*}{ RMSE } & \multirow{2}{*}{$\frac{\mathrm{THM}}{\mathrm{R}^{2}[\%]}$} & \multirow[b]{2}{*}{ MAE } & \multirow[b]{2}{*}{ RMSE } \\
\hline & & & & & & \\
\hline Periodic thermal transmittance & 99.68 & 0.0107 & 0.0214 & 99.36 & 0.0153 & 0.0302 \\
\hline Decrement factor & 97.89 & 0.0140 & 0.0272 & 96.65 & 0.0195 & 0.0341 \\
\hline Periodic thermal transmittance time shift & 99.47 & 0.0895 & 0.1959 & 99.20 & 0.1222 & 0.2419 \\
\hline External thermal admittance & 99.93 & 0.0301 & 0.0503 & 99.80 & 0.0384 & 0.0856 \\
\hline External thermal admittance time shift & 99.81 & 0.0208 & 0.0415 & 99.63 & 0.0289 & 0.0571 \\
\hline Internal thermal admittance & 95.54 & 0.1079 & 0.2153 & 93.59 & 0.1470 & 0.2582 \\
\hline Internal thermal admittance time shift & 95.39 & 0.0777 & 0.1521 & 93.28 & 0.1076 & 0.184 \\
\hline External areal heat capacity & 99.92 & 0.3811 & 0.7526 & 99.77 & 0.5420 & 1.2815 \\
\hline Internal areal heat capacity & 95.63 & 1.4320 & 2.8094 & 93.82 & 1.9433 & 3.3481 \\
\hline
\end{tabular}

Periodic thermal transmittance (MLP)
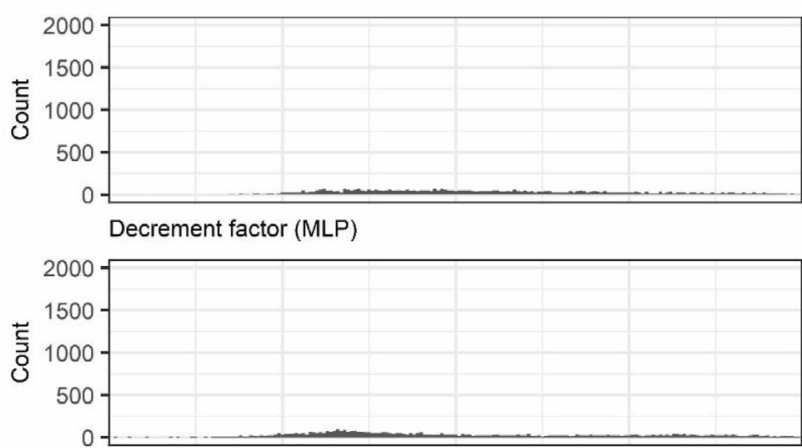

Periodic thermal transmittance time shift (MLP)

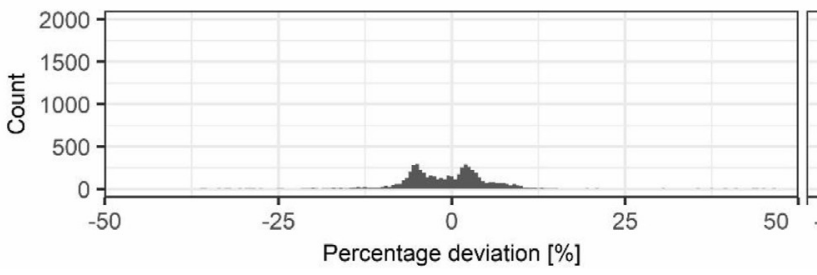

Periodic thermal transmittance (RF)

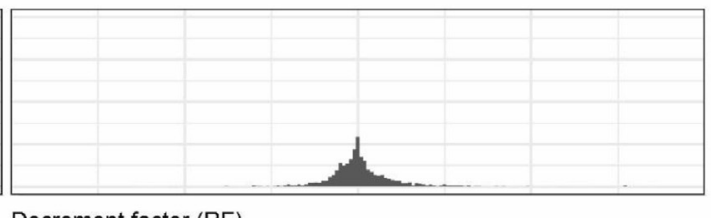

Decrement factor (RF)

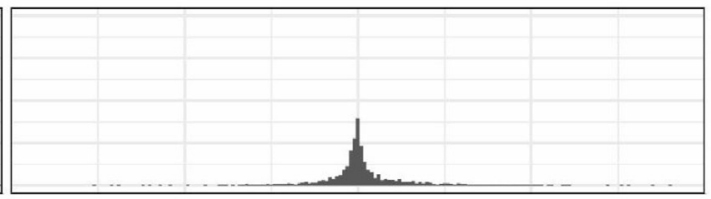

Periodic thermal transmittance time shift (RF)

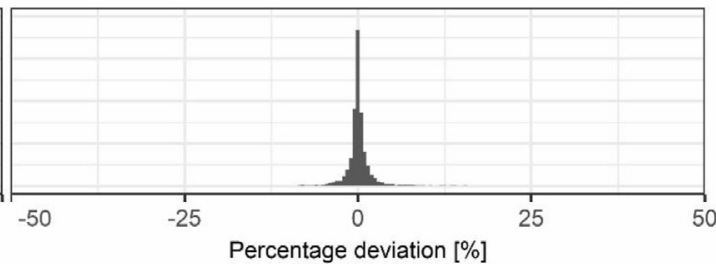

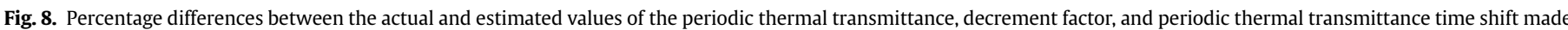
by the heat flow meter method models. The histogram bin width is $0.50 \%$.

internal surface temperature variables and HFM uses heat flux variables, and the use of different input variables affected the performances of the two models. However, the performances of the RF models were satisfactory, because they both had determination coefficients $>93 \%$ and acceptable MAEs and RMSEs.

The internal areal heat capacity, internal thermal admittance, and internal thermal admittance time shift showed worse performances than the other periodic thermal variables, meaning the models could not predict these variables well. The percentage differences between the actual and the estimated values for these variables for the 5705 instances in the testing dataset were determined. Histograms for the percentage differences for the MLP and RF models using the HFM approach are shown in Figs. 8 and 9. The percentage differences were lower for the RF models than the MLP models. Most of the periodic thermal variables had percentage differences $<25 \%$, and for many instances the percentage differences were $<10 \%$. This was also the case for the other periodic thermal variables (internal areal heat capacity, internal thermal 
External thermal admittance (MLP)

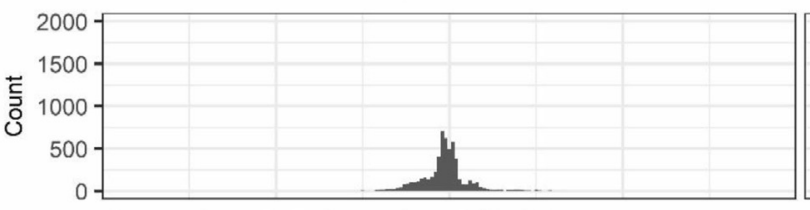

External thermal admittance time shift (MLP)

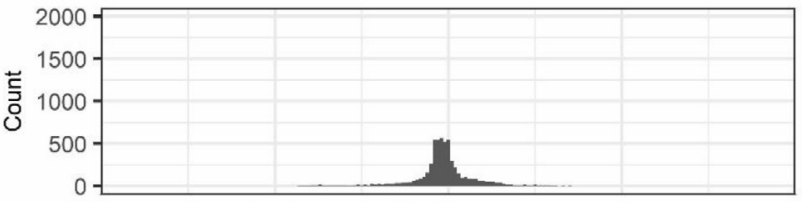

Internal thermal admittance (MLP)

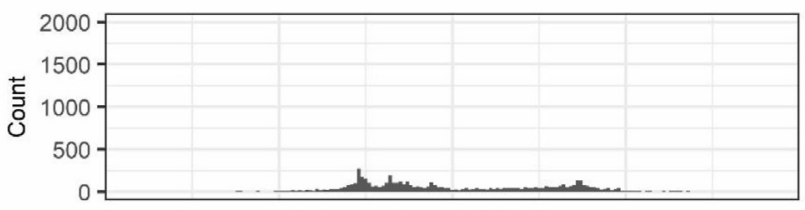

Internal thermal admittance time shift (MLP)

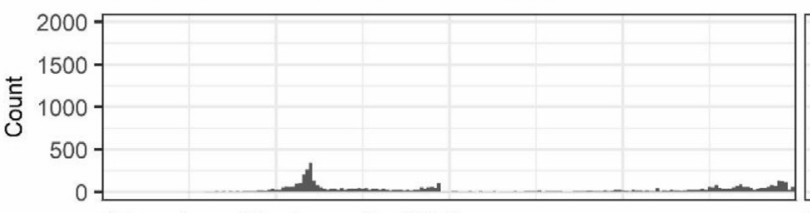

External areal heat capacity (MLP)

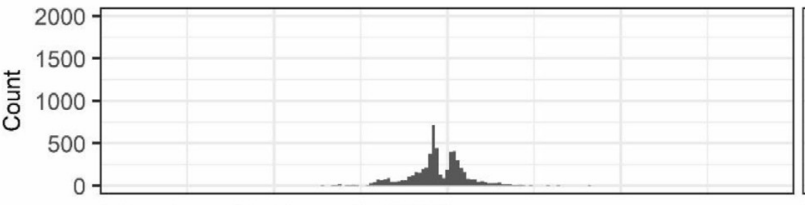

Internal areal heat capacity (MLP)

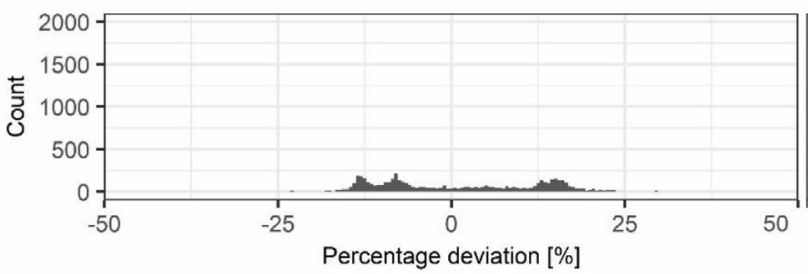

External thermal admittance (RF)

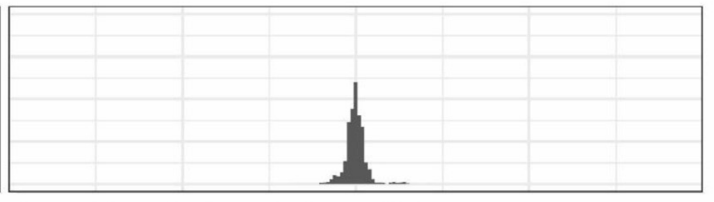

External thermal admittance time shift (RF)

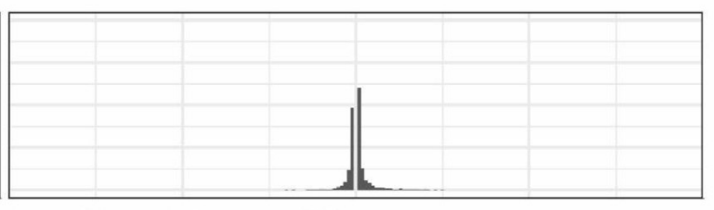

Internal thermal admittance (RF)

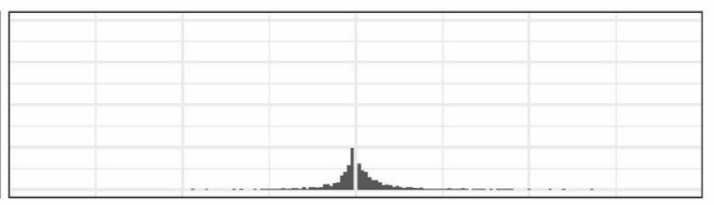

Internal thermal admittance time shift (RF)

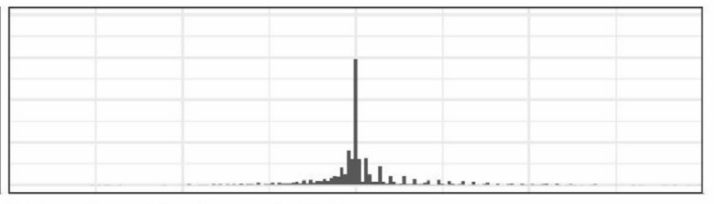

External areal heat capacity (RF)

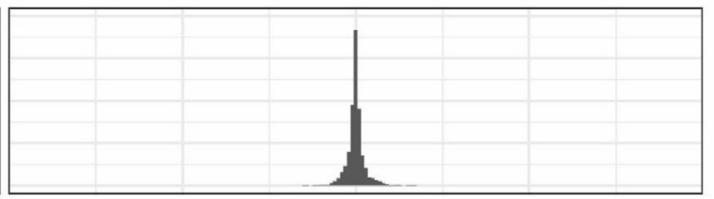

Internal areal heat capacity (RF)

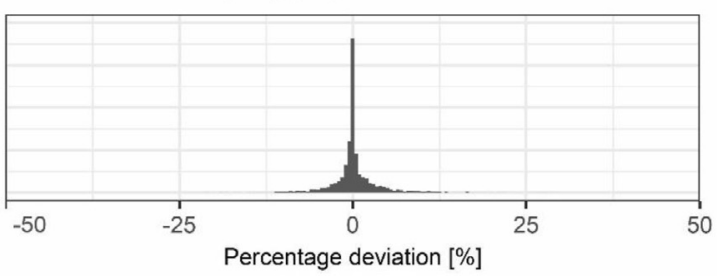

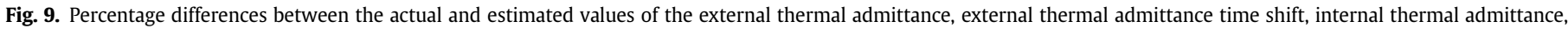

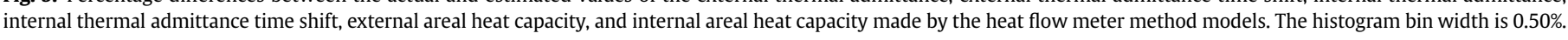

admittance, and internal thermal admittance time shift), which had slightly worse performances in terms of the statistical parameters. Only the decrement factor had percentage differences $>25 \%$ for large numbers of instances. However, this was only the case for instances with low decrement factors (close to 0 ) because a very small difference between the actual and estimated decrement factor (e.g., an actual value of 0.097 and an estimated value of 0.122 ) gave a large percentage difference. The histograms indicate that the RF algorithm gave accurate estimates of periodic thermal variables. The percentage differences were higher and there were fewer instances with percentage differences $<10 \%$ for the estimates made by the MLP models than for the estimates made by the RF models. High percentage differences were found for the periodic thermal transmittance, decrement factor, and internal thermal admittance for the MLP models. The MLP models gave acceptable estimates for some periodic thermal variables (e.g., external thermal admittance), but the RF models gave better estimates for all of the periodic thermal variables considered.
The estimates obtained using the RF model designed using the THM and HFM approaches were similar. Violin plots of the percentage differences are shown in Fig. 10. A violin plot is a type of box plot with a kernel density curve added [60]. The percentage difference distributions were similar for the RF models designed using the THM and HFM approaches. However, fewer instances with percentage differences $<1 \%$ were found for the THM models than for the HFM models, and the limit values of the violin plots were higher for the THM models than for the HFM models. The same trends were found in the estimates of the periodic thermal variables for the walls made using the RF models designed using the THM and HFM approaches. The estimates made using the HFM and THM models are shown in Tables 6 and 7, respectively. The differences between the estimated and actual values are shown. The percentage differences were all $<7 \%$, and many estimates had percentage differences $<2 \%$. The percentage differences were between $-6.83 \%$ and $2.92 \%$ for the HFM approach and $-5.81 \%$ and $4.21 \%$ for the THM approach. More acceptable estimates were 


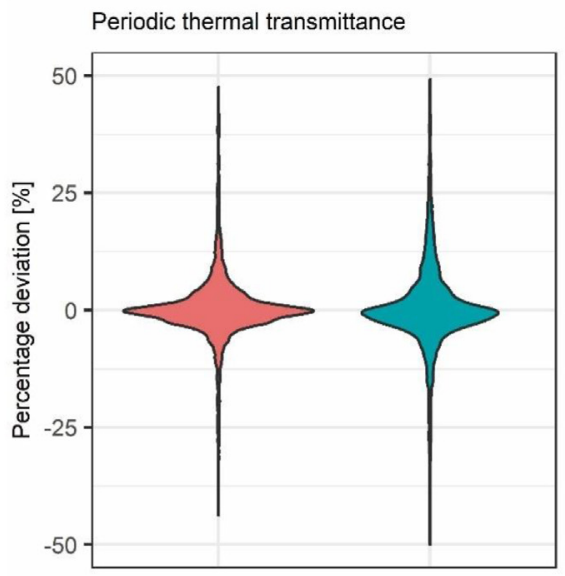

External thermal admittance

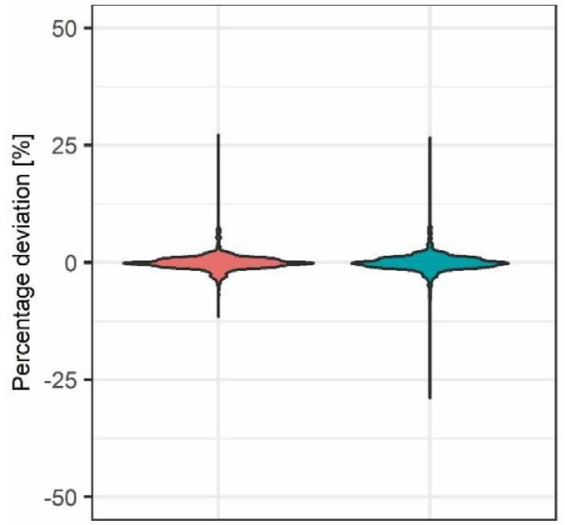

Internal thermal admittance time shift

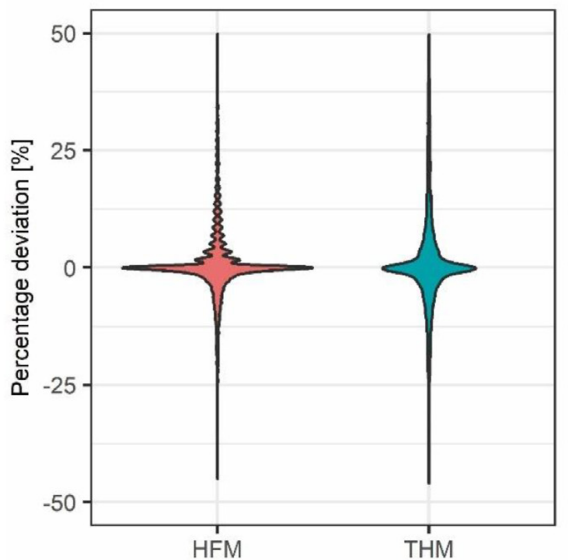

Decrement factor

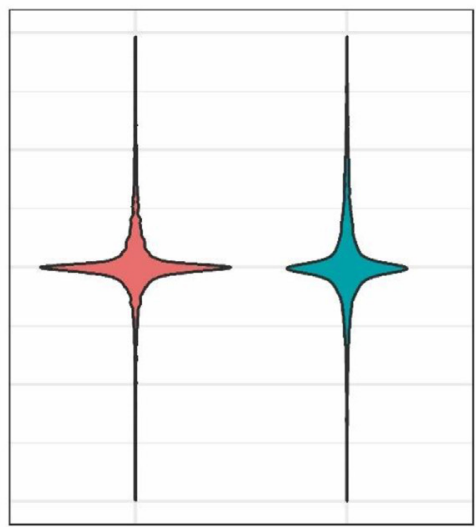

External thermal admittance time shift

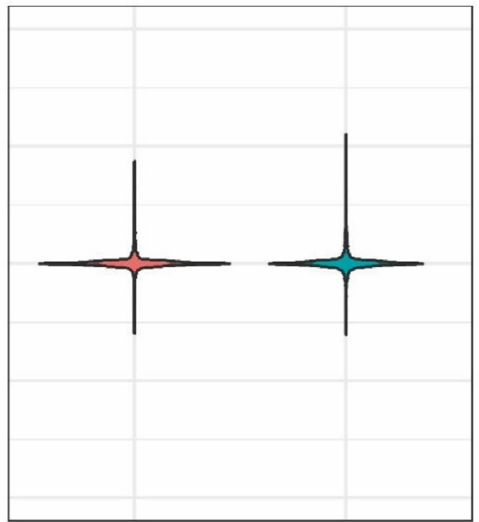

External areal heat capacity

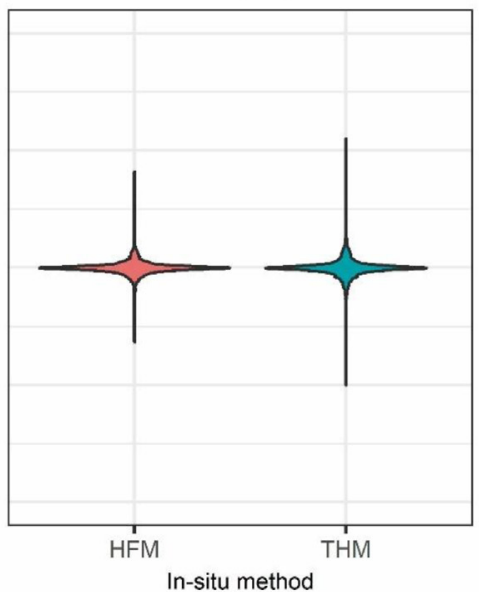

Periodic thermal transmittance time shift

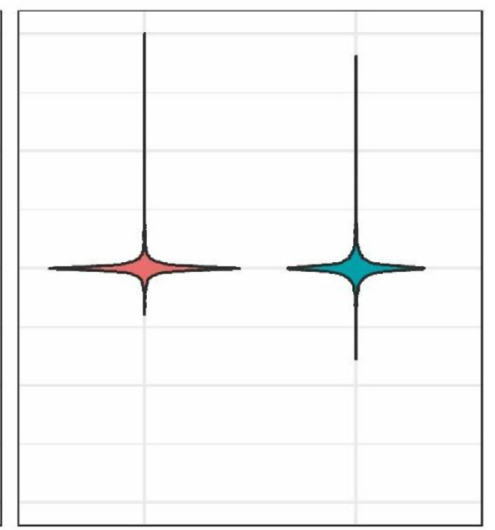

Internal thermal admittance

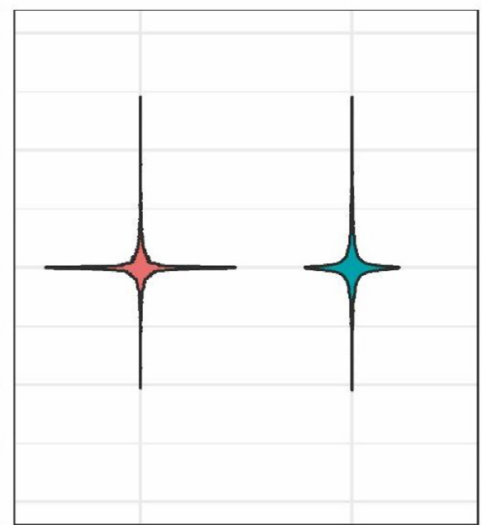

Internal areal heat capacity

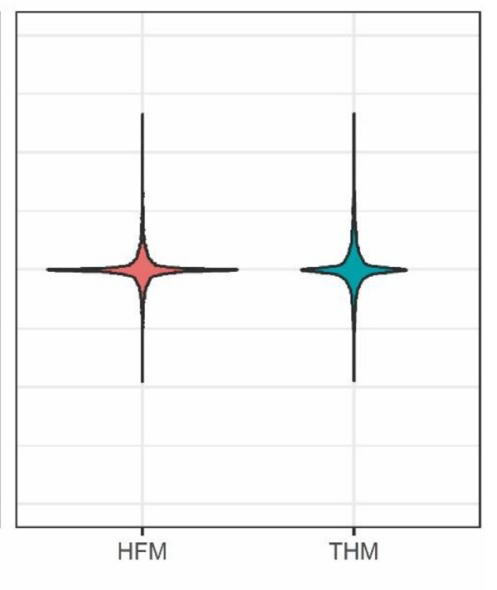

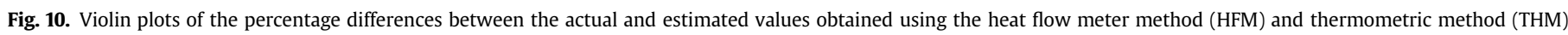
approaches.

Table 6

Estimates of the periodic thermal properties obtained using the heat flow meter method models to analyse the individual walls.

\begin{tabular}{|c|c|c|c|c|c|c|c|c|c|}
\hline \multirow[t]{2}{*}{ Variable } & \multicolumn{3}{|l|}{ W-A } & \multicolumn{3}{|l|}{ W-B } & \multicolumn{3}{|l|}{$\mathrm{W}-\mathrm{C}$} \\
\hline & Actual & Predicted & Deviation [\%] & Actual & Predicted & Deviation [\%] & Actual & Predicted & Deviation [\%] \\
\hline Periodic thermal transmittance & 0.370 & 0.374 & 0.97 & 0.277 & 0.267 & -3.68 & 0.244 & 0.250 & 2.26 \\
\hline Decrement factor & 0.283 & 0.284 & 0.40 & 0.402 & 0.390 & -2.90 & 0.428 & 0.427 & -0.18 \\
\hline Periodic thermal transmittance time shift & 8.506 & 8.502 & -0.05 & 8.364 & 8.434 & 0.83 & 6.522 & 6.508 & -0.22 \\
\hline External thermal admittance & 3.826 & 3.842 & 0.42 & 4.031 & 3.946 & -2.10 & 1.184 & 1.191 & 0.55 \\
\hline External thermal admittance time shift & 2.940 & 2.940 & 0.00 & 3.673 & 3.660 & -0.35 & 3.268 & 3.249 & -0.59 \\
\hline Internal thermal admittance & 5.192 & 5.123 & -1.34 & 3.817 & 3.867 & 1.30 & 3.846 & 3.842 & -0.09 \\
\hline Internal thermal admittance time shift & 1.171 & 1.186 & 1.31 & 2.146 & 1.999 & -6.83 & 2.137 & 2.099 & -1.77 \\
\hline External areal heat capacity & 57.657 & 57.737 & 0.14 & 59.238 & 59.101 & -0.23 & 19.191 & 19.349 & 0.82 \\
\hline Internal areal heat capacity & 75.638 & 74.944 & -0.92 & 56.035 & 57.672 & 2.92 & 55.096 & 55.575 & 0.87 \\
\hline
\end{tabular}


Table 7

Estimates of the periodic thermal properties obtained using the thermometric method models to analyse the individual walls.

\begin{tabular}{|c|c|c|c|c|c|c|c|c|c|}
\hline \multirow[t]{2}{*}{ Variable } & \multicolumn{3}{|l|}{ W-A } & \multicolumn{3}{|l|}{$W-B$} & \multicolumn{3}{|l|}{$\mathrm{W}-\mathrm{C}$} \\
\hline & Actual & Predicted & Deviation [\%] & Actual & Predicted & Deviation [\%] & Actual & Predicted & Deviation [\%] \\
\hline Periodic thermal transmittance & 0.370 & 0.386 & $4.21 \%$ & 0.277 & 0.277 & $-0.07 \%$ & 0.244 & 0.251 & $2.67 \%$ \\
\hline Decrement factor & 0.283 & 0.291 & $2.88 \%$ & 0.402 & 0.384 & $-4.40 \%$ & 0.428 & 0.427 & $-0.18 \%$ \\
\hline Periodic thermal transmittance time shift & 8.506 & 8.407 & $-1.17 \%$ & 8.364 & 8.392 & $0.33 \%$ & 6.522 & 6.554 & $0.49 \%$ \\
\hline External thermal admittance & 3.826 & 3.864 & $0.99 \%$ & 4.031 & 3.952 & $-1.95 \%$ & 1.184 & 1.196 & $0.97 \%$ \\
\hline External thermal admittance time shift & 2.940 & 2.945 & $0.17 \%$ & 3.673 & 3.639 & $-0.92 \%$ & 3.268 & 3.230 & $-1.18 \%$ \\
\hline Internal thermal admittance & 5.192 & 5.096 & $-1.86 \%$ & 3.817 & 3.898 & $2.12 \%$ & 3.846 & 3.927 & $2.12 \%$ \\
\hline Internal thermal admittance time shift & 1.171 & 1.185 & $1.23 \%$ & 2.146 & 2.021 & $-5.81 \%$ & 2.137 & 2.099 & $-1.77 \%$ \\
\hline External areal heat capacity & 57.657 & 57.986 & $0.57 \%$ & 59.238 & 59.230 & $-0.01 \%$ & 19.191 & 19.460 & $1.40 \%$ \\
\hline Internal areal heat capacity & 75.638 & 73.366 & $-3.00 \%$ & 56.035 & 57.589 & $2.77 \%$ & 55.096 & 56.668 & $2.85 \%$ \\
\hline
\end{tabular}

obtained using the THM than the HFM, and more acceptable estimates for $\mathrm{W}-\mathrm{B}$ and $\mathrm{W}-\mathrm{C}$ were obtained using the THM than the HFM, but the estimates obtained using the HFM for $\mathrm{W}-\mathrm{B}$ and $\mathrm{W}-\mathrm{C}$ also had acceptable percentage differences. The internal thermal admittance time shift obtained using the HFM and the periodic thermal transmittance, decrement factor, and internal thermal admittance time shift obtained using the THM had percentage differences $>4 \%$. This agreed with the results described above in that the variables estimated using each approach had low numbers of observations with percentage differences $<1 \%$ (see Figs. 9 and 10). It is worth noting that the differences for these variables may have been large because the values of the variables were generally low. The differences between the actual values and the values estimated using the RF model using the THM approach for W-A were $0.0186 \mathrm{~W} /\left(\mathrm{m}^{2} \mathrm{~K}\right)$ for the periodic thermal transmittance, 0.018 for the decrement factor, and $0.125 \mathrm{~h}$ for the internal thermal admittance time shift. The errors associated with the estimates of these variables were therefore acceptable for correct

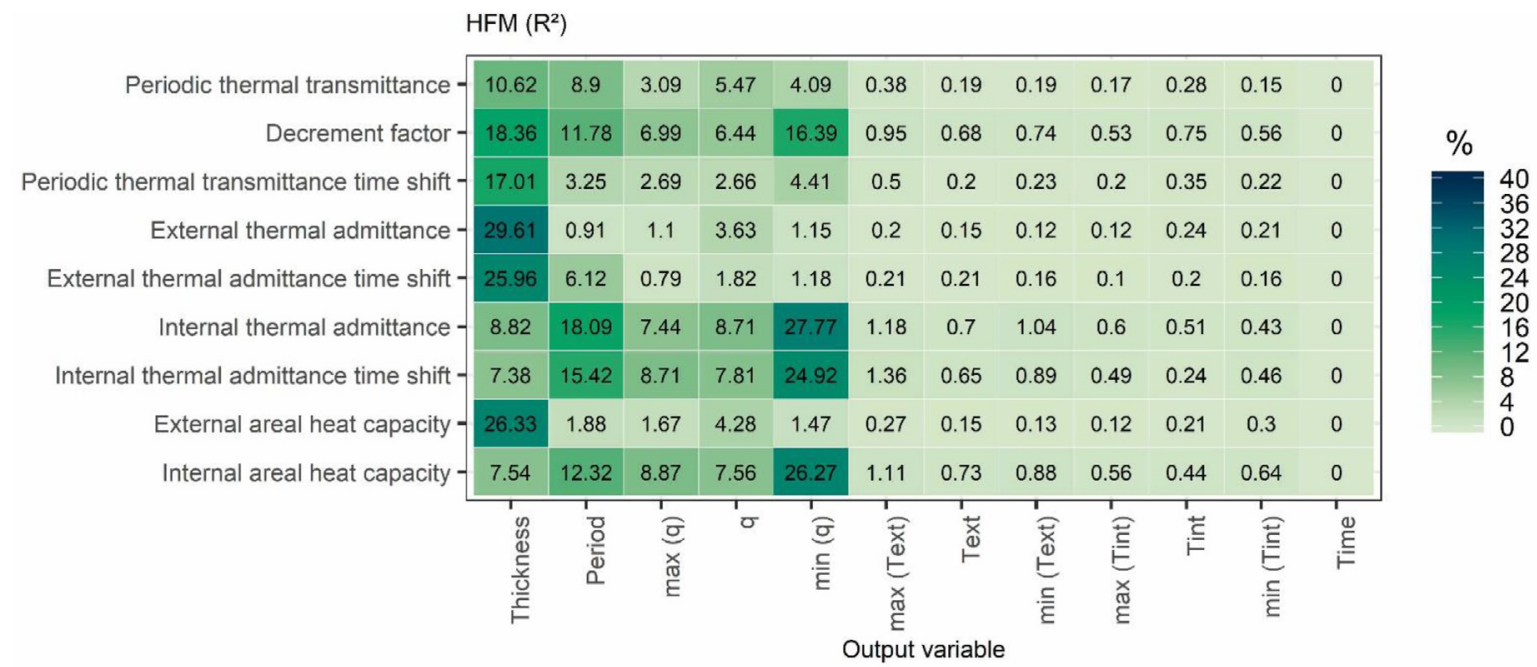

$\operatorname{THM}\left(\mathrm{R}^{2}\right)$

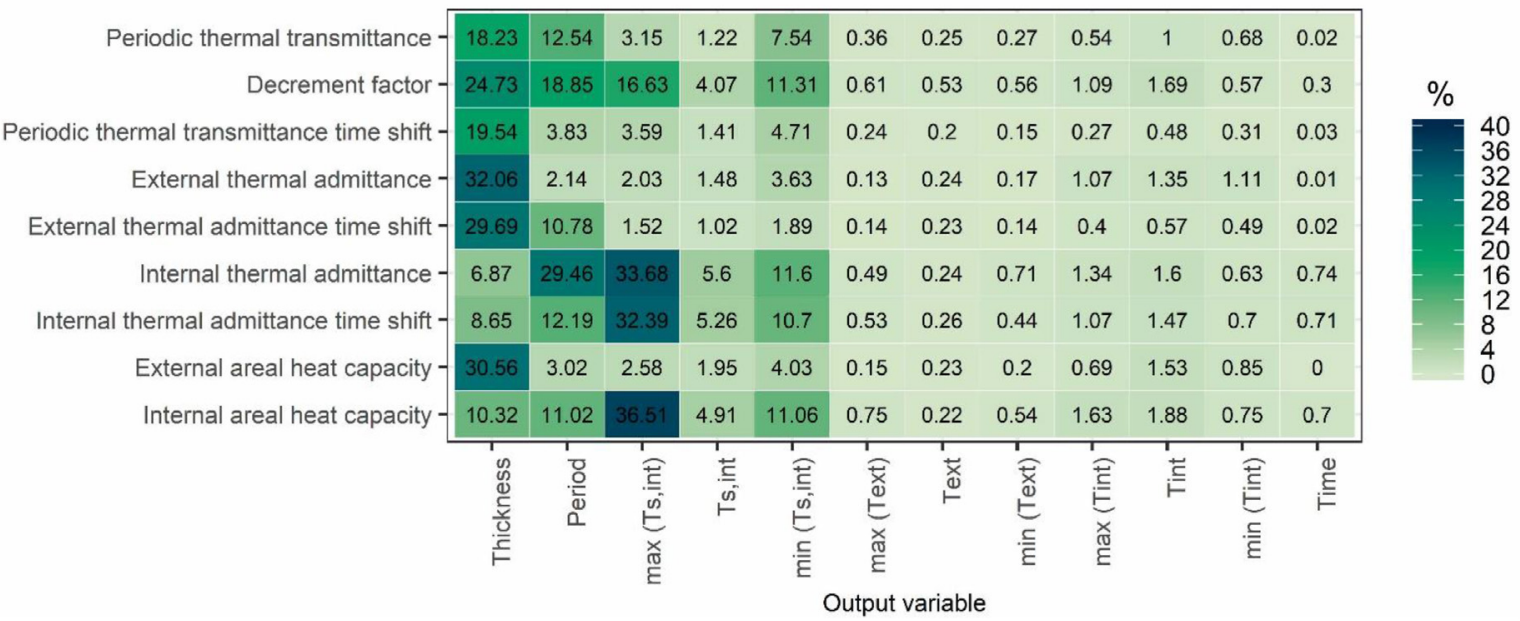

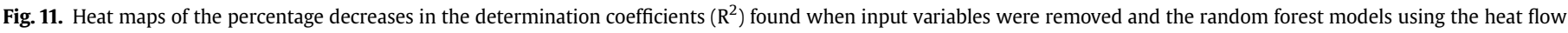
meter method and thermometric method approaches were used. 

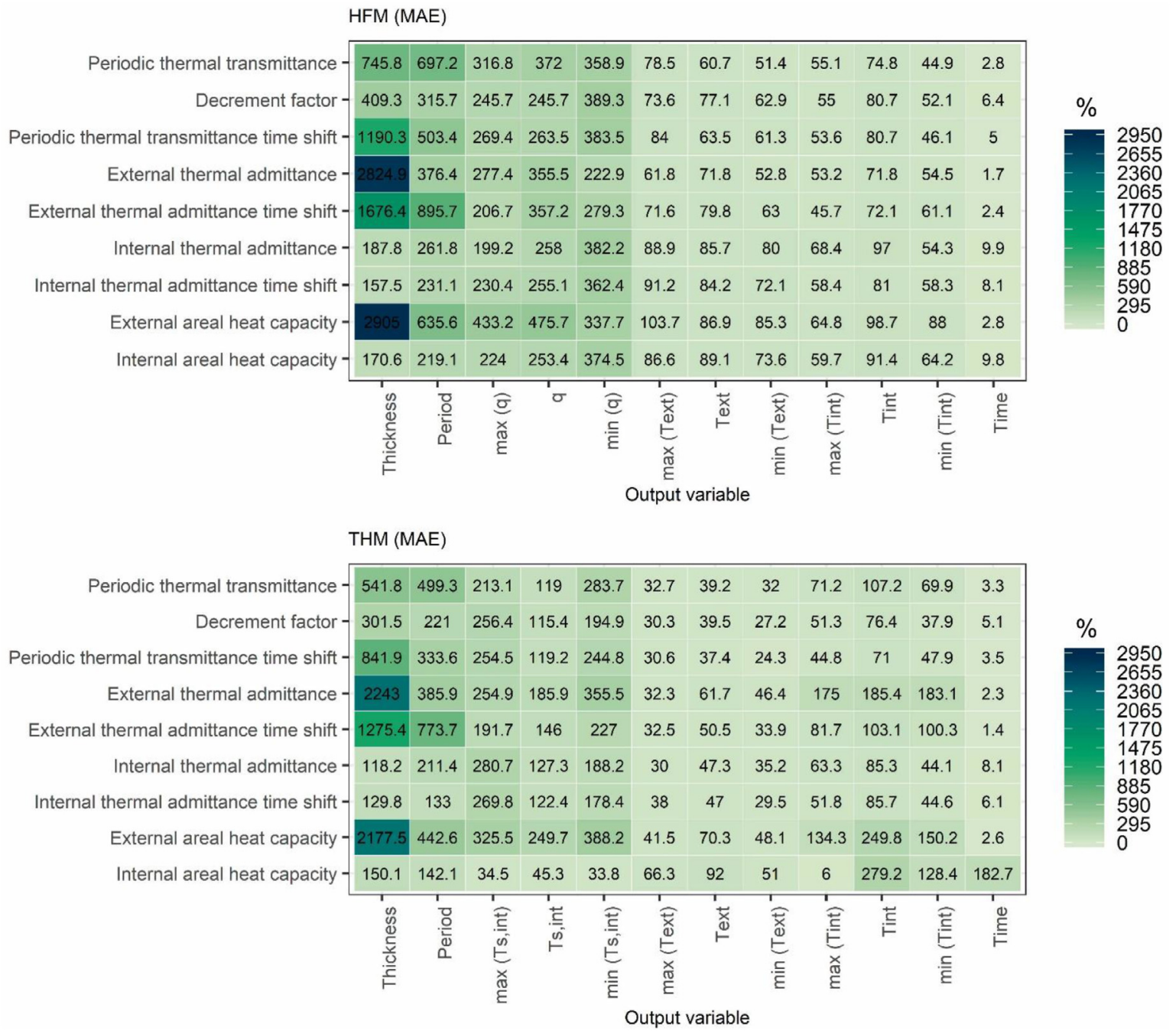

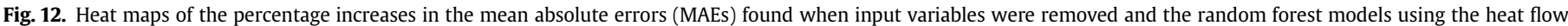
meter method and thermometric method approaches were used.

characterisation of the periodic thermal transmittances of the walls. Three of the variables that had good estimates had percentage differences $<2 \%$ when either the THM or HFM approach was used. (i) The periodic thermal transmittance time shift had percentage differences between $-0.22 \%$ and $0.83 \%$ for the HFM and between $-1.17 \%$ and $0.49 \%$ for the THM. (ii) The external thermal admittance time shift had percentage differences between $-0.59 \%$ and $0 \%$ for the HFM and between $-1.18 \%$ and $0.17 \%$ for the THM. (iii) The external areal heat capacity had percentage differences between $-0.23 \%$ and 0.82 for the HFM and between $-0.01 \%$ and $1.40 \%$ for the THM.

These results indicate the accuracies of the estimates given by the models and the potential for using the models to investigate the periodic thermal characteristics of the elements of building envelopes. The performances of the RF models when some unknown input variables were used were analysed, in order to assess the limitations of the models under actual test conditions caused either by operational errors during monitoring (e.g., a probe being disconnected) or by it not being possible to measure some input variables (e.g., identifying the building period). The analysis was performed by assessing the percentage decrease in the determination coefficient and MAE relative to the estimates performed using the test dataset (see Figs. 11 and 12). The effects of not knowing some input variables were different when estimating different periodic thermal variables. The loss of accuracy was greatest for the variables specific to each approach (i.e., heat flux for the HFM and internal surface temperature for the THM) and for the wall thickness and building period. These variables had percentage decreases in values of $\mathrm{R}^{2}$ of up to $36.51 \%$, but for the other variables the percentage decreases were up to $1.88 \%$. These results indicate that the building period strongly affects the results, as also found in a previous study [35]. Not knowing the thickness of a wall strongly affected the percentage increase in the MAE, and increases of $2824.9 \%$ and $2905 \%$ were found for the MAEs of the external thermal admittance and external areal heat capacity. This indicates that wall thickness and building period and the variables specific to each approach (heat flux and internal surface temperature) need to be well understood if the models are to perform well. The RF models give the most accurate estimates when these variables are well understood. The other variables used in the models (external and internal temperatures and time) allow the estimates of the different periodic variables to be fine-tuned, but erroneous or missing values for these variables do not necessarily cause large errors in the estimates of the different periodic variables. 


\section{Conclusions}

Results from a modelling study of thermal performance of buildings indicate that it is possible to characterise periodic thermal variables experimentally using regression algorithms. Two methods (HFM and THM) were used to characterise stationary thermal transmittance, with two regression algorithms (MLP and $\mathrm{RF}$ ). The results indicate that all of the approaches gave good estimates of the periodic thermal properties. However, the results given by the different models were not the same. Assessment of the performances of the two regression algorithms showed that the RF method was found to give better estimates than the MLP method. This finding was supported by the statistical parameters and the percentage differences between the actual and estimated values for each observation in the test dataset. The coefficients of determination were between $0.44 \%$ and $39.08 \%$ higher for the RF models than for the MLP models, and the error parameters were $65.65 \%$ 75.62\% lower for the RF models than for the MLP models. It is therefore more appropriate to use the RF method than the MLP method to estimate periodic thermal variables.

HFM and THM gave equally good estimates. The percentage differences and statistical parameters for the two methods were similar, but slightly less good statistical parameters were found for THM than for HFM. However, THM gave more accurate estimates than HFM for two out of the three walls that were analysed individually, indicating that both approaches allowed the periodic thermal properties to be characterised accurately.

Not knowing some of the input variables for the RF models affected the errors in different ways. Uncertainty in the variables specific to each approach (i.e., heat flux for the HFM and internal surface temperature for the THM) and the wall thickness and the building period gave the largest percentage differences.

The methods presented here for characterising the periodic thermal properties of building envelopes using RF models are important because they avoid the limitations of the calculations specified in ISO 13786, which require accurate information on each layer in a wall. These methods therefore represent new resources that will allow technicians responsible for improving the energy efficiencies of buildings to ensure that appropriate energy conservation measures are selected and implemented. This will allow more building renovations aimed at improving the energy efficiencies of buildings to be performed than at present, and will make it more likely that the goal of decreasing GHG emissions from buildings by the mid-21st century is met.

\section{Declaration of competing interest}

The authors declare that they have no known competing financial interests or personal relationships that could have appeared to influence the work reported in this paper.

\section{CRediT authorship contribution statement}

David Bienvenido-Huertas: Conceptualization, Methodology, Investigation, Writing - original draft. Carlos Rubio-Bellido: Conceptualization, Methodology, Investigation. Jaime SolísGuzmán: Supervision, Writing - review \& editing. Miguel José Oliveira: Supervision, Writing - review \& editing.

\section{References}

[1] World Wildlife Fund. Living planet report 2014: species and spaces, people and places, vol. 1. Gland, Switzerland: WWF International; 2014. https:/ doi.org/10.1007/s13398-014-0173-7.2.

[2] World Meteorological Organization. United in science. 2019.

[3] European Commission. A Roadmap for moving to a competitive low carbon economy in 2050. 2011. Brussels, Belgium.

4] Kurekci NA. Determination of optimum insulation thickness for building walls by using heating and cooling degree-day values of all Turkey's provincial centers. Energy Build 2016;118:197-213. https://doi.org/10.1016/ j.enbuild.2016.03.004.

[5] Vine EL, Kazakevicius E. Residential energy use in Lithuania: the prospects for energy efficiency. Energy 1999;24:591-603. https://doi.org/10.1016/S03605442(99)00013-4.

[6] Invidiata A, Lavagna M, Ghisi E. Selecting design strategies using multi-criteria decision making to improve the sustainability of buildings. Build Environ 2018;139:58-68. https://doi.org/10.1016/j.buildenv.2018.04.041.

[7] Rubio-Bellido C, Perez-Fargallo A, Pulido-Arcas JA. Optimization of annual energy demand in office buildings under the influence of climate change in Chile. Energy 2016;114:569-85. https://doi.org/10.1016/ j.energy.2016.08.021

[8] Natephra W, Yabuki N, Fukuda T. Optimizing the evaluation of building envelope design for thermal performance using a BIM-based overall thermal transfer value calculation. Build Environ 2018;136:128-45. https://doi.org/ 10.1016/j.buildenv.2018.03.032.

[9] Prada A, Cappelletti F, Baggio P, Gasparella A. On the effect of material uncertainties in envelope heat transfer simulations. Energy Build 2014;71: 53-60. https://doi.org/10.1016/j.enbuild.2013.11.083.

[10] Ramalho de Freitas J, Grala da Cunha E. Thermal bridges modeling in South Brazil climate: three different approaches. Energy Build 2018;169:271-82. https://doi.org/10.1016/j.enbuild.2018.03.044.

[11] Dodoo A, Gustavsson L, Sathre R. Effect of thermal mass on life cycle primary energy balances of a concrete-and a wood-frame building. Appl Energy 2012;92:462-72.

[12] Di Perna C, Stazi F, Casalena AU, D'Orazio M. Influence of the internal inertia of the building envelope on summertime comfort in buildings with high internal heat loads. Energy Build 2011;43:200-6. https://doi.org/10.1016/ j.enbuild.2010.09.007.

[13] Rossi M, Rocco VM. External walls design: the role of periodic thermal transmittance and internal areal heat capacity. Energy Build 2014;68:732-40. https://doi.org/10.1016/j.enbuild.2012.07.049.

[14] Ministero dello Sviluppo Economico. Decreto Ministeriale 26/6/2009 - ministero dello Sviluppo Economico Linee guida nazionali per la certificazione energetica degli edifici. 2009.

[15] Stazi F, Ulpiani G, Pergolini M, Di Perna C. The role of areal heat capacity and decrement factor in case of hyper insulated buildings: an experimental study. Energy Build 2018;176:310-24.

[16] Aste N, Angelotti A, Buzzetti M. The influence of the external walls thermal inertia on the energy performance of well insulated buildings. Energy Build 2009;41:1181-7. https://doi.org/10.1016/j.enbuild.2009.06.005.

[17] Baglivo C, Congedo PM, Fazio A, Laforgia D. Multi-objective optimization analysis for high efficiency external walls of zero energy buildings (ZEB) in the Mediterranean climate. Energy Build 2014;84:483-92. https://doi.org/ 10.1016/j.enbuild.2014.08.043.

[18] Fernandes MS, Rodrigues E, Gaspar AR, Costa JJ, Gomes Á. The impact of thermal transmittance variation on building design in the Mediterranean region. Appl Energy 2019;239:581-97. https://doi.org/10.1016/ j.apenergy.2019.01.239.

[19] Rodrigues E, Fernandes MS, Gaspar AR, Gomes Á, Costa JJ. Thermal transmittance effect on energy consumption of Mediterranean buildings with different thermal mass. Appl Energy 2019;252:113437.

[20] Gasparella A, Pernigotto G, Baratieri M, Baggio P. Thermal dynamic transfer properties of the opaque envelope: analytical and numerical tools for the assessment of the response to summer outdoor conditions. Energy Build 2011;43:2509-17. https://doi.org/10.1016/j.enbuild.2011.06.004.

[21] AENOR, UNE-EN ISO 13786. Prestaciones térmicas de los productos y componentes para edificación. Características térmicas dinámicas. Métodos de cálculo; 2011. 2011.

[22] Ficco G, Iannetta F, Ianniello E, D'Ambrosio Alfano FR, Dell'Isola M. U-value in situ measurement for energy diagnosis of existing buildings. Energy Build 2015;104:108-21. https://doi.org/10.1016/j.enbuild.2015.06.071.

[23] Asan H. Numerical computation of time lags and decrement factors for different building materials. Build Environ 2006;41:615-20. https://doi.org/ 10.1016/j.buildenv.2005.02.020.

[24] Echarri V, Espinosa A, Rizo C. Thermal transmission through existing building enclosures: destructive monitoring in intermediate layers versus nondestructive monitoring with sensors on surfaces. Sensors 2017;17:1-24. https://doi.org/10.3390/s17122848.

[25] Ballarini I, Corgnati SP, Corrado V. Use of reference buildings to assess the energy saving potentials of the residential building stock: the experience of TABULA project. Energy Pol 2014;68:273-84. https://doi.org/10.1016/ j.enpol.2014.01.027.

[26] Asdrubali F, D’Alessandro F, Baldinelli G, Bianchi F. Evaluating in situ thermal transmittance of green buildings masonries: a case study. Case Stud Constr Mater 2014;1:53-9. https://doi.org/10.1016/j.cscm.2014.04.004.

[27] Bienvenido-Huertas D, Moyano J, Marín D, Fresco-Contreras R. Review of in situ methods for assessing the thermal transmittance of walls. Renew Sustain Energy Rev 2019;102:356-71. https://doi.org/10.1016/j.rser.2018.12.016.

[28] Meng X, Yan B, Gao Y, Wang J, Zhang W, Long E. Factors affecting the in situ measurement accuracy of the wall heat transfer coefficient using the heat flow meter method. Energy Build 2015;86:754-65. https://doi.org/10.1016 
j.enbuild.2014.11.005.

[29] Ahmad A, Maslehuddin M, Al-Hadhrami LM. In situ measurement of thermal transmittance and thermal resistance of hollow reinforced precast concrete walls. Energy Build 2014;84:132-41. https://doi.org/10.1016/ j.enbuild.2014.07.048.

[30] Desogus G, Mura S, Ricciu R. Comparing different approaches to in situ measurement of building components thermal resistance. Energy Build 2011;43:2613-20. https://doi.org/10.1016/j.enbuild.2011.05.025.

[31] Grubeša IN, Teni M, Krstić H, Vračević M. Influence of freeze/thaw cycles on mechanical and thermal properties of masonry wall and masonry wall materials. Energies 2019;12:1-11. https://doi.org/10.3390/en12081464.

[32] Rotilio M, Cucchiella F, De Berardinis P, Stornelli V. Thermal transmittance measurements of the historical masonries: some case studies. Energies 2018;11:2987. https://doi.org/10.3390/en11112987.

[33] Pernigotto G, Prada A, Patuzzi F, Baratieri M, Gasparella A. Characterization of the dynamic thermal properties of the opaque elements through experimental and numerical tests. Energy Procedia 2015;78:3234-9. https:// doi.org/10.1016/j.egypro.2015.11.786.

[34] Bienvenido-Huertas D, Rubio-Bellido C, Pérez-Ordóñez JL, Oliveira MJ. Automation and optimization of in-situ assessment of wall thermal transmittance using a Random Forest algorithm. Build Environ 2020;168. https://doi.org/ 10.1016/j.buildenv.2019.106479.

[35] Bienvenido-Huertas D, Rubio-Bellido C, Pérez-Ordóñez JL, Moyano J. Optimizing the evaluation of thermal transmittance with the thermometric method using multilayer perceptrons. Energy Build 2019;198:395-411. https://doi.org/10.1016/j.enbuild.2019.06.040.

[36] Sánchez-García D, Bienvenido-Huertas D, Tristancho-Carvajal M, RubioBellido C. Adaptive comfort control implemented model (accim) for energy consumption predictions in dwellings under current and future climate conditions: a case study located in Spain. Energies 2019;12:1498. https:// doi.org/10.3390/en12081498.

[37] Carslaw HS, Jaeger JC. Conduction of heat in solids. second ed. Oxford Clarendon Press; 1959. 1959.

[38] International Organization for Standardization. ISO 6946:2007 - building components and building elements - thermal resistance and thermal transmittance - calculation method. 2007. Geneva, Switzerland.

[39] Haykin SS, Haykin SS, Haykin SS, Haykin SS. Neural networks and learning machines, vol. 3. Saddle River: Pearson Upper; 2009.

[40] Barron AR. Universal approximation bounds for superpositions of a sigmoidal function. IEEE Trans Inf Theor 1993;39:930-45.

[41] Cybenko G. Approximation by superpositions of a sigmoidal function. Math Control Signals Syst 1989;2:303-14.

[42] Hornik K, Stinchcombe M, White H. Multilayer feedforward networks are universal approximators. Neural Network 1989;2:359-66. https://doi.org/ 10.1016/0893-6080(89)90020-8.

[43] Rumelhart DE, Hinton GE, Williams RJ. Learning representations by backpropagating errors. Nature 1986;323:533-6. https://doi.org/10.1038/
$323533 \mathrm{a} 0$

[44] Wang YN. A neural network adaptive control based on rapid learning method and application. Adv Molding Anal 1994;46:27-34.

[45] Fletcher R. Practical methods of optimization. Chichester - New York - Brisbane - Toronto, United States: John Wiley \& Sons; 1980.

[46] Kohavi R. A study of cross-validation and bootstrap for accuracy estimation and model selection. Int. Jt. Conf. Artif. Intell. 1995;5. https://doi.org/10.1067/ mod.2000.109031.

[47] Assouline D, Mohajeri N, Scartezzini JL. Large-scale rooftop solar photovoltaic technical potential estimation using Random Forests. Appl Energy 2018;217: 189-211. https://doi.org/10.1016/j.apenergy.2018.02.118.

[48] Breiman L. Bagging predictors. Mach Learn 1996;24:123-40.

[49] Breiman L. Random forests. Mach Learn 2001;45:5-32. https://doi.org/ 10.1023/A:1010933404324.

[50] Rodriguez-Galiano V, Sanchez-Castillo M, Chica-Olmo M, Chica-Rivas M Machine learning predictive models for mineral prospectivity: an evaluation of neural networks, random forest, regression trees and support vector machines. Ore Geol Rev 2015;71:804-18. https://doi.org/10.1016/ j.oregeorev.2015.01.001.

[51] Zhou Y, Qiu G. Random forest for label ranking. Expert Syst Appl 2018;112: 99-109. https://doi.org/10.1016/j.eswa.2018.06.036.

[52] The Government of Spain. Approving the basic building norm NBE-CT-79 about the thermal conditions in buildings. Royal Decree 2429/79. 1979.

[53] The Government of Spain. Approving the Spanish technical building Code. Royal Decree 314/2006. 2013. Madrid, Spain.

[54] Eduardo Torroja Institute for Construction Science. Constructive elements catalogue of the CTE. 2010.

[55] Kurtz F, Monzón M, López-Mesa B. Energy and acoustics related obsolescence of social housing of Spain's post-war in less favoured urban areas. The case of Zaragoza. Inf La Construcción 2015;67:m021. https://doi.org/10.3989/ ic.14.062.

[56] Domínguez-Amarillo S, Sendra JJ, Oteiza I. La envolvente térmica de la vivienda social. El caso de Sevilla, 1939 a 1979. Madrid: Editorial CSIC; 2016.

[57] Schiavoni S, D'Alessandro F, Bianchi F, Asdrubali F. Insulation materials for the building sector: a review and comparative analysis. Renew Sustain Energy Rev 2016;62:988-1011. https://doi.org/10.1016/j.rser.2016.05.045.

[58] Pino-Mejías R, Pérez-Fargallo A, Rubio-Bellido C, Pulido-Arcas JA. Comparison of linear regression and artificial neural networks models to predict heating and cooling energy demand, energy consumption and $\mathrm{CO} 2$ emissions. Energy 2017;118:24-36. https://doi.org/10.1016/j.energy.2016.12.022.

[59] Ahmad MW, Reynolds J, Rezgui Y. Predictive modelling for solar therma energy systems: a comparison of support vector regression, random forest extra trees and regression trees. J Clean Prod 2018;203:810-21. https:/ doi.org/10.1016/j.jclepro.2018.08.207.

[60] Hintze JL, Nelson RD. Violin plots: a box plot-density trace synergism. Am Statistician 00031305.1998.10480559.
998;52:181-4. https://doi.org/10.1080/ 